\title{
Novel 1,3,4-Oxadiazole Derivatives of Pyrrolo [3,4-d]Pyridazinone Exert Anti-Inflammatory Activity without Acute Gastrotoxicity in the Carrageenan-Induced Rat Paw Edema Test
}

\author{
Marta Szandruk-Bender (D) \\ Anna Merwid-Ląd' \\ Benita Wiatrak' \\ Maciej Danielewski' \\ Stanisław Dzimira (D) ${ }^{2}$ \\ Danuta Szkudlarek ${ }^{3}$ \\ Łukasz Szczukowski ${ }^{4}$ \\ Piotr Świątek ${ }^{4}$ \\ Adam Szeląg (ID) \\ 'Department of Pharmacology, Wroclaw \\ Medical University, Wrocław, Poland; \\ ${ }^{2}$ Department of Pathology, Wroclaw \\ University of Environmental and Life \\ Sciences, Wrocław, Poland; ${ }^{3}$ Foundation \\ of the Wroclaw Medical University, \\ Wroclaw Medical University, Wrocław, \\ Poland; ${ }^{4}$ Department of Chemistry of \\ Drugs, Wroclaw Medical University, \\ Wrocław, Poland
}

Background and Purpose: Due to the risk of gastrointestinal damage and various tissue toxicity associated with non-steroidal anti-inflammatory drugs (NSAIDs) use, investigating new anti-inflammatory agents with efficacy comparable to that of NSAIDs but reduced toxicity is still a major challenge and a clinical need. Based on our previous study, new 1,3,4-oxadiazole derivatives of pyrrolo[3,4- $d]$ pyridazinone, especially 6-butyl-3,5,7-trimethyl-1-[[4-[[4-(4-nitrophenyl) piperazin-1-yl]methyl]-5-thioxo-1,3,4-oxadiazol-2-yl]methoxy]pyrrolo[3,4- $d$ ]pyridazin-4-one and 6-butyl-1-[[4-[[4-(4-chlorophenyl)-4-hydroxy-1-piperidyl]methyl]-2-thioxo-1,3,4-oxadiazol-5-yl] methoxy]-3,5,7-trimethyl-pyrrolo[3,4- $d$ ]pyridazin-4-one (hereafter referred to as the compounds $\mathbf{1 0 b}$ and $\mathbf{1 3 b}$, respectively) seem to be promising anti-inflammatory agents. This study aimed to elucidate the effects of these two new derivatives on the course of experimental rat inflammation, liver and kidney function, and gastric mucosa.

Methods: The anti-inflammatory effect of compounds $\mathbf{1 0 b}$ and $\mathbf{1 3 b}$ was evaluated using the carrageenan-induced paw edema test in rats. The increase in paw volume (paw edema), prostaglandin $\mathrm{E}_{2}\left(\mathrm{PGE}_{2}\right)$, tumor necrosis factor- $\alpha(\mathrm{TNF}-\alpha)$ and myeloperoxidase (MPO) levels, histological alterations, and inflammatory cell infiltration in paw tissue were determined. Serum alanine transaminase (ALT) and aspartate transaminase (AST) activities, serum urea and creatinine levels, as well as changes in gastric mucosa, were measured as indicators of hepatic, renal, and gastric toxicity.

Results: Pretreatment with both novel derivatives at $10 \mathrm{mg} / \mathrm{kg}$ and $20 \mathrm{mg} / \mathrm{kg}$ doses reduced paw edema, counteracted the increased $\mathrm{PGE}_{2}$ and TNF- $\alpha$ levels, reduced the influx of inflammatory cells, and decreased histopathological alterations in paw tissue. Compound $\mathbf{1 3 b}$ at a dose of $20 \mathrm{mg} / \mathrm{kg}$ was more effective than indomethacin in reversing the increased TNF- $\alpha$ levels and reducing the influx of inflammatory cells. Only compound $\mathbf{1 3 b}$ at all studied doses $(5,10$, or $20 \mathrm{mg} / \mathrm{kg}$ ) counteracted the increased MPO level in paw tissue. Both compounds neither caused alterations in ALT, AST, urea, creatinine parameters nor gastric mucosal lesions.

Conclusion: New compounds exert an anti-inflammatory effect, presumably via inhibiting inflammatory mediators release and inflammatory cell infiltration. Moreover, both possess a more favorable benefit-risk profile than indomethacin, especially compound $\mathbf{1 3 b}$.

Keywords: carrageenan, anti-inflammatory agents, pyrrolo[3,4- $d]$ pyridazinone, 1,3,4-oxadiazole, inflammatory mediators, toxicity

\section{Introduction}

Every living organism strives to achieve homeostasis. ${ }^{1}$ Many highly specialized systems and defensive mechanisms allow the organism to adapt to the surrounding
Correspondence: Marta Szandruk-Bender Department of Pharmacology, Wroclaw Medical University, Mikulicza-Radeckiego 2, Wrocław, 50-345, Poland

Tel $+487|784| 438$

Fax +48717840094

Email marta.szandruk@umed.wroc.pl 
environment and react in the event of exposure to endogenous or exogenous, infectious or non-infectious harmful stimuli. Inflammation, or inflammation response, is the organism's defensive reaction to remove or sequester the cause of the disturbance, repair the tissue, and finally restore homeostasis. ${ }^{2}$

Inflammation is characterized by such macroscopic symptoms as redness, edema, heat, pain, and loss of tissue function, which reflect elevated cellular metabolism, vasodilatation, and increased vascular permeability allowing leakage of plasma components and extravasation of immune cells. ${ }^{3}$ Plasma proteins and leukocytes, mainly neutrophils that are normally confined to the blood vessels gain access through the postcapillary venules to the extravascular tissues at the site of injury, thereby inducing edema. These vascular and cellular reactions are mediated by endogenous substances, known as inflammatory mediators, released at the site of the injury by tissue-resident immune cells, mostly macrophages, dendritic cells, and mast cells. ${ }^{4}$ Among many inflammatory mediators, proinflammatory cytokines and bioactive lipids - particularly tumor necrosis factor- $\alpha(\mathrm{TNF}-\alpha)$ and prostaglandin $\mathrm{E}_{2}$ $\left(\mathrm{PGE}_{2}\right)$ - are considered to be the main ingredients that initiate and govern the inflammatory process. ${ }^{2}$ In addition to typical inflammatory markers, the enzyme myeloperoxidase (MPO), released upon neutrophil activation, deserves special attention as a protein with proinflammatory properties independent of its enzymatic activity. These cytokinelike properties can modulate the activation state of leukocytes during inflammatory diseases. ${ }^{5,6}$

Although the inflammatory response is one of the organism's defensive mechanisms against harmful factors, it is unpleasant for the patient, often causing suffering and sometimes not leading to recovery either. In principle, a controlled inflammatory response in appropriate amounts is beneficial to the organism, though it can become detrimental if dysregulated due to its tissue-damaging potential. $^{2}$ Usually, the inflammatory response is terminated once the triggering insult is eliminated and damaged tissue is repaired. If inflammatory response is prolonged, inefficient, or excessive, a chronic inflammatory state may ensue. This process, characterized by persistent production of proinflammatory cytokines and proinflammatory lipids, may lead to aberrant tissue remodeling, irreversible damage, and chronic disorders such as inflammatory bowel disease, atherosclerosis, asthma, or neurodegenerative disorders, which inevitably lead to impaired quality of life, loss of time from work or education, disability, and untimely death. ${ }^{7,8}$ While many anti-inflammatory agents are available today, including non-steroidal antiinflammatory drugs (NSAIDs), glucocorticoids, and biological agents, all of them have some limitations in terms of safety and efficacy., ${ }^{3,9}$ Therefore, there is still an unmet clinical need and a challenge for medicinal chemists to develop more effective and safer agents to treat the signs and symptoms of acute inflammation, thereby preventing its evolving into a chronic condition that leads to irreversible changes.

In this context, one of the promising strategies used in medicinal chemistry to identify new compounds is to combine a structure with known anti-inflammatory properties with a moiety capable of enhancing this activity. The pyrrolo[3,4- $d]$ pyridazinone core is a structure that exerts anti-inflammatory activity. ${ }^{10,11}$ In turn, diversely substituted five-membered rings of 1,3,4-oxadiazole-2-thione, which is a bioisosteric analog of the carboxyl group, exhibit various biological activities - including antiinflammatory activity. ${ }^{12-15}$ Moreover, anti-inflammatory compounds possessing this five-membered ring show decreased gastrotoxicity. ${ }^{13,14}$ Drugs used worldwide, eg, ibuprofen, diclofenac, or naproxen, were modified similarly. The obtained derivatives of the mentioned drugs, including in their structure a 1,3,4-oxadiazole-2-thione ring, show significant anti-inflammatory activity and diminished gastrointestinal adverse effects. ${ }^{13,14,16}$

Inspired by this research, we designed, synthesized, and investigated the series of novel derivatives of pyrrolo [3,4- $d]$ pyridazinone linked with 1,3,4 oxadiazole-2-thione pharmacophore. ${ }^{12,17,18}$ According to in silico and in vitro assays we performed, new molecules strongly inhibit cyclooxygenase (COX) activity, show superior affinity towards isoform COX-2, and some of them act as selective COX-2 inhibitors. ${ }^{12,17}$ In our previous in vivo study, the most promising novel pyrrolo[3,4- $d]$ pyridazinone derivatives - 6-butyl-3,5,7-trimethyl-1-[[4-[[4-(4-nitrophenyl) piperazin-1-yl]methyl]-5-thioxo-1,3,4-oxadiazol-2-yl] methoxy]pyrrolo[3,4- $d$ ]pyridazin-4-one and 6-butyl1-[[4-[[4-(4-chlorophenyl)-4-hydroxy-1-piperidyl]methyl]2-thioxo-1,3,4-oxadiazol-5-yl]methoxy]-3,5,7-trimethylpyrrolo[3,4- $d]$ pyridazin-4-one (hereafter referred to as the compounds 10b and 13b, respectively) - exerted dosedependent antinociceptive activity with reduced gastrotoxicity in noxious stimuli induced models of pain, ie, the tail-flick and formalin test. ${ }^{18}$ It is well known that nociception and inflammation are functionally linked at multiple levels. Tissue damage is detected by both 
nociceptors that enable pain sensation in the affected area and by tissue-resident cells, which induce an inflammatory response. Exudate formation, tissue edema, and inflammatory mediators are responsible for inflammatory pain, and nociception replenishes inflammatory sensors in tissue homeostasis monitoring. ${ }^{7,19}$ Since compounds $\mathbf{1 0 b}$ and 13b counteract inflammatory nociception in the late phase of the formalin test, compound $\mathbf{1 3 b}$ even in a more efficient way than indomethacin, ${ }^{18}$ we decide to assess whether these novel compounds also exert antiinflammatory action.

The current study was undertaken to elucidate the effect of pretreatment with newly synthesized pyrrolo $[3,4-d]$ pyridazinone derivatives, compounds $\mathbf{1 0 b}$ or $\mathbf{1 3 b}$, on the course of acute carrageenan-induced paw inflammation. Additionally, the levels of inflammatory mediators, such as $\mathrm{PGE}_{2}$, TNF- $\alpha$, and MPO, as well as the magnitude of infiltration with inflammatory cells are going to be checked to explain the possible mechanisms of action of the newly synthesized compounds. Moreover, this study was aimed at assessing the influence of new derivatives on liver and kidney function and gastric mucosa.

\section{Materials and Methods Drugs and Chemicals}

The studied compounds - two novel derivatives of pyrrolo $[3,4-d]$ pyridazinone named $\mathbf{1 0 b}$ and $\mathbf{1 3 b}$ - were prepared and characterized as reported earlier. ${ }^{12}$ Analysis of the $1 \mathrm{H}$ NMR, 13C NMR, MS, FT-IR, and elemental analysis as well as physicochemical features showed spectroscopic and analytical properties of the newly obtained derivatives to be in agreement with their assigned structure. Indomethacin, in subst. and $\lambda$-carrageenan, in subst. were purchased from Sigma Aldrich (Steinheim, Germany); carboxymethylcellulose (CMC), in subst. and formalin 37\%, sol. were obtained from PolAura (Olsztyn, Poland); pentobarbital sodium + pentobarbital $133.3 \mathrm{mg} / \mathrm{mL}+26.7 \mathrm{mg} / \mathrm{mL}$, sol. was purchased from Biowet (Puławy, Poland); medetomidine hydrochloride $1 \mathrm{mg} / \mathrm{mL}$, sol. was supplied from OrionPharma (Warszawa, Poland); normal saline was obtained from Polpharma (Starogard Gdański, Poland). Other chemicals used were included in the commercially available kits.

\section{Animals}

The Wistar rats (210-260 g) were obtained from the Animal Research Center at Wroclaw Medical University (Wrocław, Poland). All animals were accustomed to the laboratory condition for 7 days before commencing the experiments. The rats were housed, two per cage, in polypropylene cages with enrichments in a standard laboratory environment with a $12 / 12 \mathrm{~h}$ light/dark cycle, a humidity of $55-60 \%$ and a temperature of $21-24^{\circ} \mathrm{C}$, with water ad libitum and free access to standard animal feed (Agropol, Motycz, Poland), except for the single procedure of deprivation.

\section{Ethical Considerations}

The current study was carried out with the permission (Resolution No. 101/2018 of 12.12.2018) of the Local Ethics Committee for Animal Experiments in Wrocław at Hirszfeld Institute of Immunology and Experimental Therapy of Polish Academy of Sciences (Wrocław, Poland). The animal care and all experimental procedures were by the applicable international, national, and institutional guidelines, including the Act of 15 January 2015 on the protection of animals used for scientific and educational purposes (Journal of Laws of 2015, item 266) and the EU directive 2010/63/EU.

\section{Study Protocol}

After seven days of adaptation, the animals were randomly allotted to nine groups (twelve animals per group) organized as follows:

- One group pretreated with $0.5 \%$ CMC solution (vehicle) intragastrically (i.g.) and injected subplantarly (s. pl.) with normal saline (control group, C);

- One group pretreated with $0.5 \% \mathrm{CMC}$ i.g. and injected s.pl. with $1 \%$ carrageenan solution (carrageenan group, Car);

- One group pretreated with indomethacin at a dose of $10 \mathrm{mg} / \mathrm{kg}$ i.g. and injected s.pl. with $1 \%$ carrageenan solution (indomethacin group, Ind);

- And 6 groups pretreated i.g. with compound $10 \mathrm{~b}$ or 13b at the doses of 5,10 , or $20 \mathrm{mg} / \mathrm{kg}$ and injected s. pl. with $1 \%$ carrageenan solution $(\mathbf{1 0 b}-5, \mathbf{1 0 b}-10$, 10b-20, 13b-5, 13b-10, 13b-20 groups, respectively).

The $0.5 \% \mathrm{CMC}$ solution and studied substances suspended in $0.5 \% \mathrm{CMC}$ solution were given in a single dose by a gastric tube (FST, Foster City, CA, USA) in a volume of $4 \mathrm{~mL} / \mathrm{kg}$. Prior to the administration of the appropriate substance, rats were food-deprived for $12 \mathrm{~h}$. Doses of tested compounds and indomethacin were selected based on the earlier works. ${ }^{11,18,20,21}$ One hour after appropriate substance administration, the carrageenan-induced paw edema test (carrageenan-induced inflammation) was performed. After the test, 
blood for biochemical assays was taken from the tail vein, centrifugated (15 min at $4000 \mathrm{rpm}$ ), and the obtained serum samples were kept at $-80^{\circ} \mathrm{C}$ until further analysis. The rats were then sacrificed by intramuscular injection of medetomidine $(0.5 \mathrm{mg} / \mathrm{kg})$ followed by intraperitoneal injection of pentobarbital $(200 \mathrm{mg} / \mathrm{kg})$, and the right hind paw and the stomach were immediately dissected. Afterward, inflammatory exudate of the carrageenan-injected paw was collected for histopathological assessment. Then, one part of each right hind paw was fixed in 4\% buffered formalin for histopathological analysis, and the soft tissue from the remaining part was homogenized (Homogenizer PRO250, PRO Scientific Inc., Oxford, CT, USA), with the obtained supernatants stored at $-80^{\circ} \mathrm{C}$ for inflammatory markers evaluation. The excised stomachs were opened along the greater curvature, gently cleared of the contents by dipping in normal saline, macroscopically examined, and fixed in 4\% buffered formalin for histopathological assessment.

\section{Carrageenan-Induced Paw Edema Test}

Inflammation in rats was induced by carrageenan injection according to the procedure described by Winter et al. $^{22}$ After $1 \mathrm{~h}$ of appropriate substance administration, rats were injected once with $1 \%$ carrageenan solution in normal saline under the subplantar aponeurosis area of the right hind paw in a volume of $0.1 \mathrm{~mL}$, except the control group in which rats were injected with normal saline given by the same route and in equivalent volume. The right hind paw of each rat was marked with ink at the level of the lateral malleolus and paw volume was measured up to this mark. The volume of the injected paw of each animal was measured plethysmometrically (Plethysmometer 37140, UgoBasile, Gemonio, Italy) before (time 0 ) and at 1, 2, 3, and $6 \mathrm{~h}$ after (time 1, 2, $3,6)$ carrageenan or saline subplantar injection. For each time point, measurement was repeated three times and the average was then calculated. All measurements were performed by the same investigator to reduce any potential inter-operator variability. The paw edema was expressed as the relative increase in paw volume quantified by measuring the difference between the paw volume before and at $1,2,3$, and $6 \mathrm{~h}$ after carrageenan or normal saline injection according to the equation:

$$
\operatorname{paw} \operatorname{edema}(m l)=V_{t}-V_{0}
$$

where $\mathrm{V}_{\mathrm{t}}$ is the paw volume at $\mathrm{t} \mathrm{h}$ after (time $1,2,3,6$ ) carrageenan or normal saline injection $(\mathrm{mL}) ; \mathrm{V}_{0}$ is the paw volume before (time 0 ) carrageenan or normal saline injection $(\mathrm{mL})$. The paw edema measured in the time intervals was used to calculate the percentage of paw edema inhibition using the following equation:

$$
\text { inhibition of paw edema }(\%)=\left(1-E_{t} / E_{\text {car }}\right) \times 100
$$

where $\mathrm{E}_{\mathrm{t}}$ is the edema volume of treated animals $(\mathrm{mL}) ; \mathrm{E}_{\mathrm{car}}$ is the edema volume of carrageenan-injected animals $(\mathrm{mL})$.

\section{Assessment of PGE 2 , TNF- $\alpha$, and MPO Levels in Paw Tissue}

The concentrations of $\mathrm{PGE}_{2}$, TNF- $\alpha$, and MPO were measured in obtained supernatants with enzyme-linked immunosorbent assay (ELISA) kits: Rat $\mathrm{PGE}_{2}$ ELISA Kit, Rat TNF- $\alpha$ ELISA Kit, Rat MPO ELISA Kit, (Cloud-Clone Corp., Katy, TX, USA) following the manufacturer's instructions. All concentrations were expressed as $\mathrm{pg} / \mathrm{mL}$.

\section{Microscopic Assessment of Paw Tissue}

The formalin-fixed paw specimens were embedded in paraffin, sectioned to $4 \mu \mathrm{m}$ slices, mounted on the glass slides, stained by the routine hematoxylin-eosin (H\&E) method, and examined using an Olympus BX53 light microscope combined with an Olympus UC90 camera (Olympus, Germany) at 200x magnification. Histopathological evaluation of inflammation indicatives was performed in a blinded fashion by an experienced pathologist using the $0-5$-point scale presented previously by Mert et $\mathrm{al}^{23}$ and described in detail in the legend for Table 1.

\section{Microscopic Assessment of Paw Exudate}

Cell blocks from inflammatory exudates of the paw were prepared by a tissue clot method (by allowing a clot to form in the lumen of the fine needle aspiration tip). ${ }^{24}$ The clot was then transferred directly to $4 \%$ buffered formalin for fixation, embedded in paraffin, and cut into $4 \mu \mathrm{m}$-thick slices, which were mounted on the glass slides and stained by the routine H\&E method. All slides were assessed in a blinded way by an independent pathologist for the presence of inflammatory cells (neutrophils, lymphocytes, monocytes) using an Axiolab 5 light microscope combined with an Axiocam 208 color camera (Zeiss, Jena, Germany) at 400x magnification in 40 high power fields (HPF).

\section{Assessment of Serum Biochemical Parameters}

The activities of alanine transaminase (ALT), aspartate transaminase (AST), and urea and creatinine levels in rat 
Table I The Impact of Compounds I Ob and I3b on Microscopic Changes of Paw Tissue and the Number of Inflammatory Cells in Exudate in H\&E Staining. Indomethacin Was Used as a Reference Drug

\begin{tabular}{|c|c|c|}
\hline Group & Microscopic Changes in H\&E Staining (0-5 Points) & Number of Inflammatory Cells in I HPF of Exudate Sample \\
\hline C & 0 & 0 \\
\hline Car & $4.20 \pm 0.20 * * *$ & $40.10 \pm 1.50 * * *$ \\
\hline Ind & $1.80 \pm 0.20 * * * \ldots \#$ & $18.30 \pm 1.25 * * * \#$ \\
\hline IOb-5 & $3.35 \pm 0.2^{* * *^{\wedge \wedge \wedge}}$ & $39.80 \pm 0.68^{* * * *^{\wedge \wedge}}$ \\
\hline $10 b-10$ & $3.10 \pm 0.23 * * *^{\# \wedge}$ & $36.30 \pm 1.5 I^{* * * *^{\wedge \wedge}}$ \\
\hline $10 b-20$ & $2.80 \pm 0.25 * * * *^{\wedge}$ & 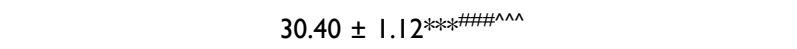 \\
\hline I3b-5 & $3.30 \pm 0.21 * * * \wedge \wedge$ & $34.20 \pm 1.65 * * * \#^{\wedge \wedge \wedge}$ \\
\hline $13 \mathbf{b}-10$ & $2.90 \pm 0.28 * * * \# \wedge$ & $21.60 \pm 1.19 * * * \ldots \#$ \\
\hline 13b-20 & $2.00 \pm 0.26 * * * \ldots \#$ & $9.20 \pm 1.38^{* * * \# \# \wedge \wedge \wedge}$ \\
\hline
\end{tabular}

Notes: Experimental groups: C - control group; Car - carrageenan group; Ind - group receiving 10 mg/kg indomethacin; I Ob-5, I0b-10, and I0b-20 - groups receiving, respectively, 5, 10, or $20 \mathrm{mg} / \mathrm{kg}$ of compound 10b; I3b-5, I3b-10, and I3b-20 - groups receiving, respectively, 5, 10, or $20 \mathrm{mg} / \mathrm{kg}$ of compound I3b. Scoring scale of microscopic assessment of paw tissue damage: $(0)=$ no inflammation; $(I)=$ mild inflammation; $(2)=$ mild or moderate inflammation; $(3)=$ moderate inflammation; $(4)=$ moderate or severe inflammation; $(5)=$ severe inflammation. ${ }^{* * *} p<0.001$ vs control group; ${ }^{\#} p<0.05,{ }^{\#} p<0.01,{ }^{\# \#} p<0.001$ vs carrageenan group; ${ }^{\wedge} p<0.05,{ }^{\wedge} p<0.01$, ${ }^{\wedge \wedge} \mathrm{P}<0.00 \mathrm{I}$ vs indomethacin group.

Abbreviation: HPF, high power field.

serum were measured in a certified laboratory using Architect c4000 equipment and commercial ALT (Ref 8L92-20 8L92-40), AST (Ref 8L91-20 8L91-40), Urea (Ref 7D75-20 7D75-30) and Creatinine (Ref 7D64-20) Architect Abbott Kits (Abbott, Wiesbaden, Germany) following the manufacturer's instructions.

\section{Macro- and Microscopic Assessment of Gastric Mucosa}

The damage to gastric mucosa was evaluated macroand microscopically. The severity of macroscopic mucosal changes was assessed using the 0-3-point scale described in the legend for Table 2, according to the criteria previously presented by Szabo et $\mathrm{al}^{25}$ Afterwards, formalin-fixed stomach specimens were embedded in paraffin and cut into $4 \mu \mathrm{m}$ thick sections, which were mounted on the glass slides and stained by the routine H\&E method. Then, the microscopic analysis was performed using an Olympus BX53 light microscope combined with an Olympus UC90 camera (Olympus, Germany). Histopathological changes of stomach tissue sections were examined at $100 x$ magnification and assessed using the 0-3-point scale described in the legend for Table 2 .

\section{Statistical Analysis}

All data are presented as mean values \pm standard error of the mean (SEM). The one-way analysis of variance (ANOVA) and multiple comparisons with Scheffe's post hoc test were used to analyze the statistical significance of differences among studied groups. The multi-criteria

Table 2 The Impact of Compounds I Ob and I3b on Gastric Mucosa. Indomethacin Was Used as a Reference Drug

\begin{tabular}{|c|c|c|}
\hline Group & Macroscopic Lesions (0-3 Points) & Microscopic Lesions in H\&E Staining (0-3 Points) \\
\hline C & 0 & 0 \\
\hline Car & 0 & 0 \\
\hline Ind & $2.25 \pm 0.19 * * *$ & $2.35 \pm 0.17^{* * *}$ \\
\hline IOb-5 & $0^{\wedge \wedge \wedge}$ & $0^{\wedge \wedge \wedge}$ \\
\hline $10 b-10$ & $0.15 \pm 0.08^{\wedge \wedge \wedge}$ & $0.20 \pm 0.08^{\wedge \wedge \wedge}$ \\
\hline $10 b-20$ & $0.53 \pm 0.11^{\wedge \wedge \wedge}$ & $0.36 \pm 0.11^{\wedge \wedge \wedge}$ \\
\hline $13 b-5$ & $0^{\wedge \wedge}$ & $0^{\wedge \wedge \wedge}$ \\
\hline $13 \mathbf{b}-10$ & $0^{\wedge \wedge \wedge}$ & $0.050 .05^{\wedge \wedge \wedge}$ \\
\hline $13 \mathbf{b}-20$ & $0.34 \pm 0.07^{\wedge \wedge}$ & $0.32 \pm 0.07^{\wedge \wedge}$ \\
\hline
\end{tabular}

Notes: Experimental groups: C - control group; Car - carrageenan group; Ind - group receiving $10 \mathrm{mg} / \mathrm{kg}$ indomethacin; I0b-5, I0b-10, and I0b-20 - groups receiving, respectively, 5, 10, or $20 \mathrm{mg} / \mathrm{kg}$ of compound $10 \mathbf{b}$; I3b-5, I3b-10, and I3b-20 - groups receiving, respectively, 5, 10 , or $20 \mathrm{mg} / \mathrm{kg}$ of compound I3b. Scoring scale of macroscopic assessment of gastric mucosa: $(0)=$ no damage; $(I)=1-4$ small petechiae; $(2)=5$ or more petechiae or hemorrhagic streaks up to 4 mm; $(3)=$ erosions longer than $5 \mathrm{~mm}$ or confluent hemorrhages. Scoring scale of microscopic assessment of gastric mucosa: $(0)=$ no damage; $(I)=$ mild changes; $(2)=$ moderate changes; $(3)=$ severe changes. Data are presented as mean values $\pm \operatorname{SEM}(n=12) .{ }^{* * *} p<0.001$ vs control group; ${ }^{\wedge \wedge} p<0.001$ vs indomethacin group. 
decision analysis (MCDA) using the weighted sum model (WSM) was executed to compare the pharmacological and toxicological properties of the studied compounds. Equal weights were set for each bioassay performed. All statistical analyses were performed using GraphPad Prism version 8.0 (GraphPad Software, San Diego, CA, USA) and Statistica version 13.3 (StatSoft, Kraków, Poland) with a $p$-value $<0.05$ considered as the significance level.

\section{Results}

\section{The Effects of Pyrrolo[3,4- $d]$ Pyridazinone} Derivatives on the Carrageenan-Induced Paw Edema in Rats

To assess the anti-inflammatory activity of the novel pyrrolo[3,4- $d]$ pyridazinone derivatives - compounds 10b and 13b - carrageenan-induced paw edema was performed. The absolute rat paw volume and relative increase in paw volume (paw edema) before and at 1, 2, 3 , and $6 \mathrm{~h}$ after carrageenan or normal saline injection in all experimental groups are shown in Figures $1 \mathrm{~A}$ and $\mathrm{B}$, respectively. Detailed data of the absolute rat paw volume (mean values \pm SEM including the level of significance between groups) are presented in Supplementary Material, Table S1. Detailed data of the paw edema (mean values \pm SEM including the level of significance between groups and the percentage of paw edema inhibition) are presented in Table 3. There were no significant differences in rat paw volume before the carrageenan or normal saline injection between the experimental groups $(p=N S)$. Subplantar injection of
$0.1 \mathrm{~mL}$ of $1 \%$ carrageenan solution into the rat hind paw caused severe discernible inflammation with a significant increase in paw volume (paw edema) at $1,2,3$, and $6 \mathrm{~h}$ after injection $(\mathrm{p}<0.001$ vs control group in all comparisons; Figure $2 \mathrm{~A}$ and $\mathrm{B}$ ). The maximum paw edema was observed in each studied group at 6 $\mathrm{h}$ after carrageenan administration. Pretreatment of rats with the studied compounds, $\mathbf{1 0 b}$ or $\mathbf{1 3 b}$, resulted in an inhibition of paw edema starting from $2 \mathrm{~h}$ after carrageenan injection (Figure 2D and E). Pretreatment with compound $10 \mathrm{~b}$ at a dose of 10 or $20 \mathrm{mg} / \mathrm{kg}$ partly reversed the carrageenan-induced increase in paw volume at 2,3 , and $6 \mathrm{~h}(\mathrm{p}<0.001$ vs carrageenan group and $\mathrm{p}<0.001$ vs control group in all comparisons). At the low dose $(5 \mathrm{mg} / \mathrm{kg})$, compound $\mathbf{1 0 b}$ partly inhibited the carrageenan-induced edema only at $2 \mathrm{~h}(\mathrm{p}<0.05$ vs carrageenan group and $p<0.001$ vs control group). At all examined doses, compound $\mathbf{1 3 b}$ partly reversed the increase in paw volume at 2, 3, and $6 \mathrm{~h}$ after carrageenan injection $(\mathrm{p}<0.001$ vs carrageenan group for 10 and $20 \mathrm{mg} / \mathrm{kg}$ dose; $\mathrm{p}<0.01, \mathrm{p}<0.001$, and $\mathrm{p}<0.05$ vs carrageenan group for $5 \mathrm{mg} / \mathrm{kg}$ dose at 2,3 , and $6 \mathrm{~h}$, respectively). For all studied doses of compound $\mathbf{1 3 b}$ at 2,3 , and $6 \mathrm{~h}$ the differences versus the control group were still significant $(p<0.001$ in all cases $)$. Administration of reference drug indomethacin before carrageenan injection also caused a significant inhibition of paw edema (Figure 2C) at 2, 3, and $6 \mathrm{~h}$ of carrageenan test, wherein at $3 \mathrm{~h}$ indomethacin completely reversed the increase in paw volume $(p<0.001$ vs carrageenan group; $p=N S$ vs control group) and at 2 and $6 \mathrm{~h}$ indomethacin partly

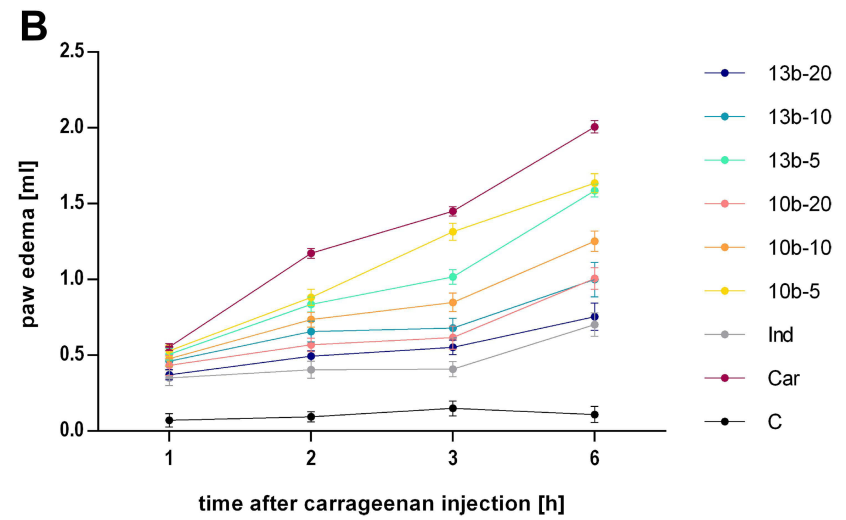

Figure I The impact of compounds IOb and I3b on the paw volume (A) and the increase in paw volume (paw edema) (B) after carrageenan injection. Indomethacin was used as a reference drug. Experimental groups: $\mathrm{C}-$ control group receiving $0.5 \% \mathrm{CMC}$ intragastrically (i.g.) and normal saline subplantarly (s.pl.); Car - carrageenan group receiving $0.5 \% \mathrm{CMC}$ i.g. and $1 \%$ carrageenan solution s.pl.; Ind - indomethacin group receiving $10 \mathrm{mg} / \mathrm{kg}$ of indomethacin i.g. and $1 \%$ carrageenan solution s.pl.; $10 \mathrm{~b}-5$, $10 \mathrm{~b}-$ I0, and I Ob-20 - groups receiving, respectively, 5, I0, or 20 mg/kg of investigated compound I Ob i.g. and I\% carrageenan solution s.pl.; I 3b-5, I3b-I0, and I3b-20 - groups receiving, respectively, 5,10 , or $20 \mathrm{mg} / \mathrm{kg}$ of investigated compound I3b i.g. and I\% carrageenan solution s.pl. Data are presented as mean values $\pm \mathrm{SEM}$ ( $\mathrm{n}=12$ ). 
Table 3 The Impact of Compounds I Ob and I3b on the Increase in Paw Volume (Paw Edema) and the Percentage of Paw Edema Inhibition After Carrageenan Injection. Indomethacin Was Used as a Reference Drug

\begin{tabular}{|c|c|c|c|c|}
\hline \multirow[t]{2}{*}{ Group } & I h & $2 \mathrm{~h}$ & $3 \mathbf{h}$ & $6 \mathrm{~h}$ \\
\hline & \multicolumn{4}{|c|}{ Increase in Paw Volume (Paw Edema; mL) Paw Edema Inhibition (\%) } \\
\hline C & $0.07 \pm 0.05$ & $0.09 \pm 0.04$ & $0.15 \pm 0.04$ & $0.11 \pm 0.04$ \\
\hline Car & $0.56 \pm 0.02 * * *$ & $1.16 \pm 0.03 * * *$ & $1.46 \pm 0.03 * * *$ & $2.01 \pm 0.03 * * *$ \\
\hline Ind & $0.37 \pm 0.05(33.56 \%)^{*}$ & 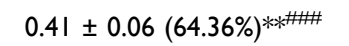 & $0.42 \pm 0.06(71.22 \%)^{\# \#}$ & $0.71 \pm 0.06(64.41 \%)^{* * *}$ \\
\hline 10b-5 & $0.53 \pm 0.04(4.36 \%)^{* * *}$ & $0.88 \pm 0.05(24.18 \%)^{* * * \# \wedge \wedge \wedge}$ & $1.31 \pm 0.05(10.02 \%)^{* * *^{\wedge \wedge \wedge}}$ & $1.64 \pm 0.06(18.01 \%)^{* * * *^{\wedge \wedge}}$ \\
\hline $10 b-10$ & $0.49 \pm 0.04(12.62 \%)^{* * *}$ & 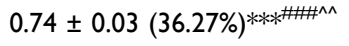 & 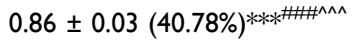 & 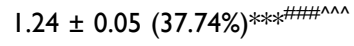 \\
\hline $10 b-20$ & $0.43 \pm 0.06(22.54 \%)^{* * *}$ & $0.57 \pm 0.05(50.88 \%)^{* * *}$ & $0.62 \pm 0.04(57.53 \%)^{* * * \ldots \# \#}$ & $1.04 \pm 0.05(48.09 \%)^{* * * \ldots \#}$ \\
\hline I3b-5 & $0.5 \mathrm{I} \pm 0.04(8.77 \%)^{* * *}$ & $0.83 \pm 0.04(28.45 \%)^{* * * \#^{* \wedge \wedge}}$ & $1.02 \pm 0.05(29.98 \%)^{* * * \# \# \# \wedge \wedge \wedge}$ & $1.59 \pm 0.07(20.50 \%)^{* * * \#^{\wedge \wedge \wedge}}$ \\
\hline $13 b-10$ & $0.47 \pm 0.04(15.86 \%)^{* * *}$ & $0.66 \pm 0.05(42.90 \%)^{* * *}$ & 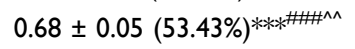 & $1.00 \pm 00.08(50.25 \%)^{* * * \# \# \wedge \wedge}$ \\
\hline 13b-20 & $0.37 \pm 0.03(33.15 \%)^{* *}$ & $0.49 \pm 0.04$ (57.56\%)***\#\# & $0.55 \pm 0.04(62.33 \%)^{* * * \# \# ~}$ & $0.76 \pm 0.04(62.19 \%) * * * \#$ \\
\hline
\end{tabular}

Notes: Experimental groups: C - control group; Car - carrageenan group; Ind - group receiving $10 \mathrm{mg} / \mathrm{kg}$ indomethacin; 10b-5, $10 \mathrm{~b}-10$, and 10b-20 - groups receiving, respectively, 5, 10, or $20 \mathrm{mg} / \mathrm{kg}$ of compound 10b; 13b-5, 13b-10, and 13b-20 - groups receiving, respectively, 5, 10, or $20 \mathrm{mg} / \mathrm{kg}$ of compound I3b. Data are presented as mean values \pm SEM $(n=12) .{ }^{*} p<0.05$, ${ }^{* *} p<0.01$, ${ }^{* * *} p<0.001$ vs control group; $\# p<0.05$, \# $<<0.01$, \#\#p $<0.001$ vs carrageenan group; ${ }^{\wedge \wedge} p<0.01,{ }^{\wedge \wedge}{ }^{\wedge}<0.001$ vs indomethacin group.

reversed the carrageenan-induced paw edema $(\mathrm{p}<0.001$ vs carrageenan group; $\mathrm{p}<0.01$ and $\mathrm{p}<0.001$ vs control group, respectively). Neither the studied compounds nor indomethacin exerted significant activity at $1 \mathrm{~h}$ after carrageenan injection $(\mathrm{p}=\mathrm{NS}$ vs carrageenan group and $p<0.001$ vs control group in all cases). The maximum inhibitory effect in the treated groups compared to the carrageenan group was observed at $3 \mathrm{~h}$ of carrageenan test after administration of indomethacin at a dose of $10 \mathrm{mg} / \mathrm{kg}$ (71.2\% inhibition of paw edema) as well as after the administration of compound $\mathbf{1 0 b}$ or $\mathbf{1 3 b}$ at the high dose $(57.5 \%$ and $62.3 \%$, respectively). Moreover, pretreatment with compound $10 \mathbf{b}$ or $\mathbf{1 3 b}$ at the high dose inhibited paw edema at all studied time points in a manner comparable to that of indomethacin. There were no significant differences in paw edema between the group receiving $20 \mathrm{mg} / \mathrm{kg}$ of compound $\mathbf{1 0 b}$ or $\mathbf{1 3 b}$ and the indomethacin-receiving group $(\mathrm{p}=\mathrm{NS})$. The action of compound $\mathbf{1 3} \mathbf{b}$ given at a dose of $10 \mathrm{mg} / \mathrm{kg}$ at $2 \mathrm{~h}$ was also comparable to that provided by indomethacin $(p=N S)$.

\section{The Effects of Pyrrolo[3,4- $d]$ Pyridazinone Derivatives on $\mathrm{PGE}_{2}, \mathrm{TNF}-\alpha$, and MPO Levels in the Carrageenan-Injected Rat Paw}

The enzyme-linked immunosorbent assay tests were performed to evaluate the effects of compounds $\mathbf{1 0 b}$ and $\mathbf{1 3 b}$ on the levels of $\mathrm{PGE}_{2}, \mathrm{TNF}-\alpha$, and MPO, the increase of which takes place in the inflammatory response. The concentrations of these proinflammatory parameters (mean \pm $\mathrm{SEM}$ ) in paw tissue are presented in Figure 3A-C. Injection of carrageenan into the rat paw caused a significant increase in the $\mathrm{PGE}_{2}, \mathrm{TNF}-\alpha$, and MPO levels in paw tissue in comparison to the control group ( $p<0.001$, $\mathrm{p}<0.001$, and $\mathrm{p}<0.01$, respectively). Pretreatment with compound 10b at a dose of $10 \mathrm{mg} / \mathrm{kg}$ or $20 \mathrm{mg} / \mathrm{kg}$ prevented the increase in the $\mathrm{PGE}_{2}$ level in paw tissue compared to the
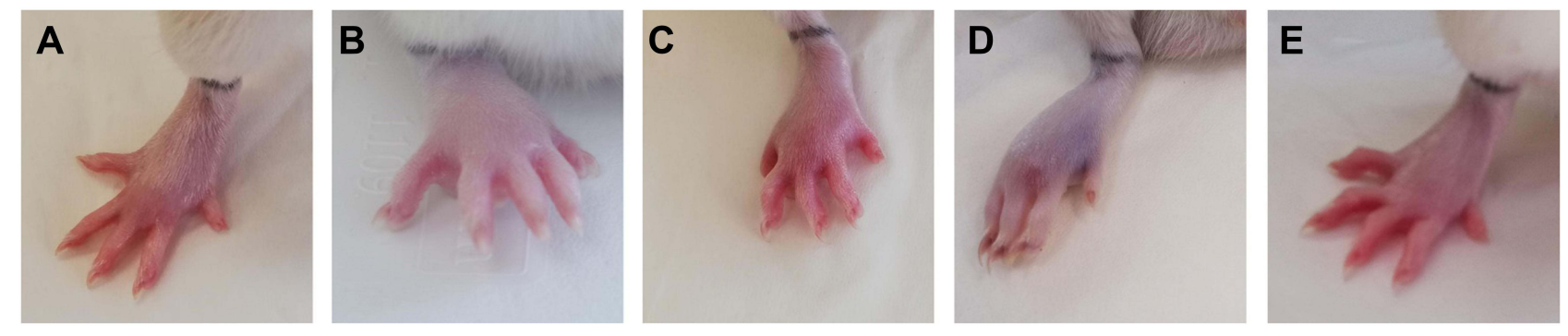

Figure 2 The effects of compounds $\mathbf{1 0 b}$ and $\mathbf{I} \mathbf{3} \mathbf{b}$ on the carrageenan-induced paw edema in rats. Indomethacin was used as a reference drug. Experimental groups: control group (A); carrageenan group (B); group receiving $10 \mathrm{mg} / \mathrm{kg}$ indomethacin (C); group receiving $20 \mathrm{mg} / \mathrm{kg}$ compound IOb (D); group receiving $20 \mathrm{mg} / \mathrm{kg}$ compound I3b (E). 

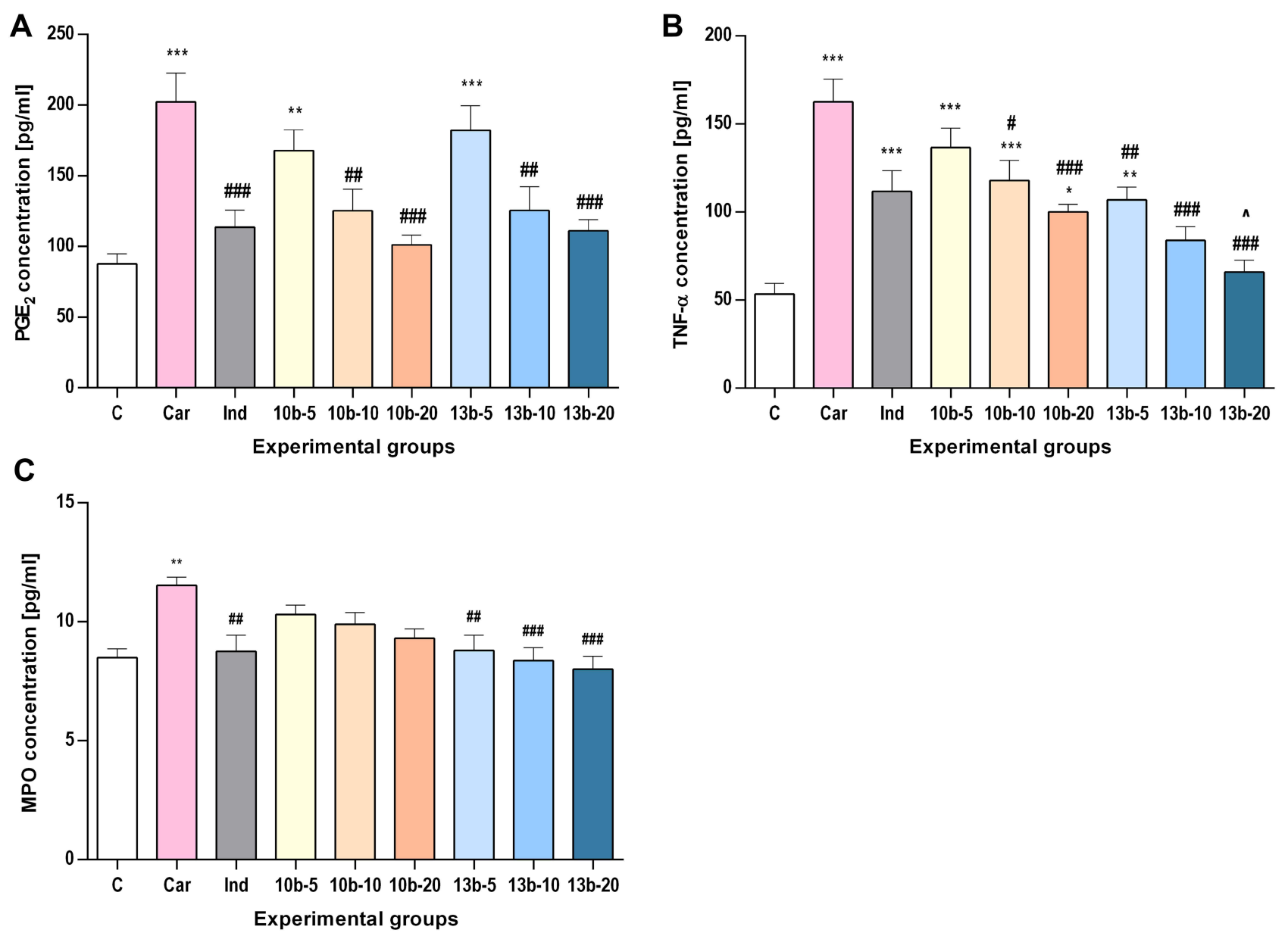

Figure 3 The impact of compounds $\mathbf{I O b}$ and $\mathbf{I} \mathbf{3 b}$ on PGE $\mathbf{2}(\mathbf{A})$, TNF- $\alpha(\mathbf{B})$, and MPO (C) concentrations in paw tissue. Indomethacin was used as a reference drug. Experimental groups: $\mathrm{C}$ - control group receiving $0.5 \% \mathrm{CMC}$ intragastrically (i.g.) and normal saline subplantarly (s.pl.); Car - carrageenan group receiving $0.5 \% \mathrm{CMC}$ i.g. and I\% carrageenan solution s.pl.; Ind - indomethacin group receiving $10 \mathrm{mg} / \mathrm{kg}$ of indomethacin i.g. and I\% carrageenan solution s.pl.; $10 \mathrm{~b}-5$, $10 \mathrm{~b}-10$, and $10 \mathrm{~b}-20$ - groups receiving, respectively, 5, 10, or $20 \mathrm{mg} / \mathrm{kg}$ of investigated compound I 0b i.g. and I\% carrageenan solution s.pl.; I3b-5, I3b-10, and I3b-20 - groups receiving, respectively, 5, 10 , or $20 \mathrm{mg} / \mathrm{kg}$ of investigated compound I 3b i.g. and I\% carrageenan solution s.pl. Data are presented as mean values \pm SEM ( $n=12$ ). Differences * $<0.05$ vs control group;

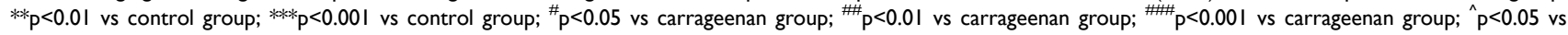
indomethacin group were deemed statistically significant.

group of carrageenan-injected animals ( $\mathrm{p}<0.01$ and $\mathrm{p}<0.001$, respectively). $\mathrm{PGE}_{2}$ concentrations in these two treated groups were not different from the control group $(p=N S)$. Administration of compound 10b at a dose of $10 \mathrm{mg} / \mathrm{kg}$ or $20 \mathrm{mg} / \mathrm{kg}$ partly reversed the alteration in TNF- $\alpha$ tissue concentration $(\mathrm{p}<0.05, \mathrm{p}<0.001$ vs carrageenan group; $\mathrm{p}<0.001, \mathrm{p}<0.05$ vs control group, respectively). The low dose of compound $10 \mathbf{b}(5 \mathrm{mg} / \mathrm{kg})$ did not exert significant activity against the carrageenan-induced increase in $\mathrm{PGE}_{2}$ and TNF- $\alpha$ tissue level ( $p=$ NS vs carrageenan group; $p<0.01$ and $p<0.001$ vs control group, respectively). The concentrations of MPO in groups receiving compound $\mathbf{1 0 b}$ in all studied doses were not significantly different from that in the carrageenan group, but they did not differ significantly from the control group either $(\mathrm{p}=\mathrm{NS})$. Pretreatment with compound 13b at a dose of $10 \mathrm{mg} / \mathrm{kg}$ or $20 \mathrm{mg} / \mathrm{kg}$ counteracted the increased $\mathrm{PGE}_{2}$, TNF- $\alpha$, and MPO levels in paw tissue compared to the group of carrageenan-injected animals ( $p<0.01$ for $\mathrm{PGE}_{2}$ for the $10 \mathrm{mg} / \mathrm{kg}$ dose and $\mathrm{p}<0.001$ for others). The difference to the control group was insignificant in all these cases $(\mathrm{p}=\mathrm{NS})$. Administered at the low dose ( $5 \mathrm{mg} / \mathrm{kg}$ ), compound 13b protected from the increase of MPO concentration $(p<0.01$ vs carrageenan group and $p=$ NS vs control group), partly reversed the altered TNF- $\alpha$ level ( $<<0.01$ vs carrageenan and control group) and did not affect $\mathrm{PGE}_{2}$ concentration $(\mathrm{p}=\mathrm{NS}$ vs carrageenan group and $\mathrm{p}<0.001 \mathrm{vs}$ control group). Indomethacin $(10 \mathrm{mg} / \mathrm{kg})$ given before carrageenan injection prevented the increase of $\mathrm{PGE}_{2}$ and MPO tissue levels $(p<0.001, p<0.01$ vs carrageenan group, $\mathrm{p}=\mathrm{NS}$ vs control group) and partly reversed the increased TNF- $\alpha$ level $(p<0.01$ vs carrageenan group and $\mathrm{p}<0.001$ vs control group). Compound $\mathbf{1 0 b}$ or $\mathbf{1 3 b}$ 
administered at a medium or high dose normalized the $\mathrm{PGE}_{2}$ concentration in a manner comparable to that of indomethacin $(p=N S)$. Following pretreatment with compound $\mathbf{1 0 b}$ or 13b at each dose tested, the TNF- $\alpha$ and MPO levels were normalized in a manner comparable to that of indomethacin $(\mathrm{p}=\mathrm{NS})$. Additionally, compound 13b given at a dose of $20 \mathrm{mg} / \mathrm{kg}$ counteracted the increased TNF- $\alpha$ level more effectively than indomethacin $(\mathrm{p}<0.05)$, causing a nearly 2-fold greater decrease in the TNF- $\alpha$ level in comparison to indomethacin $(59.42 \%$ vs $31.20 \%)$.

\section{The Effects of Pyrrolo[3,4-d]Pyridazinone Derivatives on Carrageenan-Induced Histopathological Alterations in Paw}

To investigate whether the studied compounds counteract carrageenan-induced changes in the paw tissue, histopathological analysis of paw tissue was performed. Table 1 shows the scoring of paw tissue samples. Microscopic examination of paw tissue of carrageenan-injected rats showed massive inflammation with pronounced interstitial and intermuscular edema, inflammatory cell infiltration, and loss of normal muscle paw architecture (Figure 4B) compared to the control group with no histological damage $(p<0.001$;
Figure 4A). Infiltration of inflammatory cells, including enormous numbers of neutrophils, lymphocytes, and sparse mast cells, was localized in connective tissue and between muscle bundles (Figure 4B). Following pretreatment with the studied compounds at a dose of 10 or $20 \mathrm{mg} / \mathrm{kg}$, there was an explicit recovery of carrageenan-injected paw tissue with decreased edema and dispersion of muscle bundles and reduced inflammatory cell infiltration (Figure 4E, F, H and I). Scoring of paw tissue samples indicated that in comparison to the carrageenan group, compound $\mathbf{1 0 b}$ or $\mathbf{1 3 b}$ administered at the medium or high dose remarkably diminished the carrageenan-induced alterations in paw tissue $(p<0.05$ and $\mathrm{p}<0.01$ for compound $\mathbf{1 0 b} ; \mathrm{p}<0.01$ and $\mathrm{p}<0.001$ for compound $\mathbf{1 3 b}$, respectively). The tissue sections from the hind paws of rats receiving compound $\mathbf{1 3 b}$ at a dose of $20 \mathrm{mg} / \mathrm{kg}$ or indomethacin showed a weak inflammatory reaction with nearly normal paw tissue histological architecture (Figure 4C and I) while the effect of compound 13b at the high dose was comparable to that of indomethacin ( $\mathrm{p}=$ NS). Pretreatment with compound $\mathbf{1 0 b}$ or $\mathbf{1 3 b}$ at the low dose $(5 \mathrm{mg} / \mathrm{kg})$ showed only a slight improvement in edema formation and inflammatory cell infiltration (Figure 4D and $\mathrm{G})$, and this effect was insignificant when compared to the carrageenan group $(\mathrm{p}=\mathrm{NS})$.
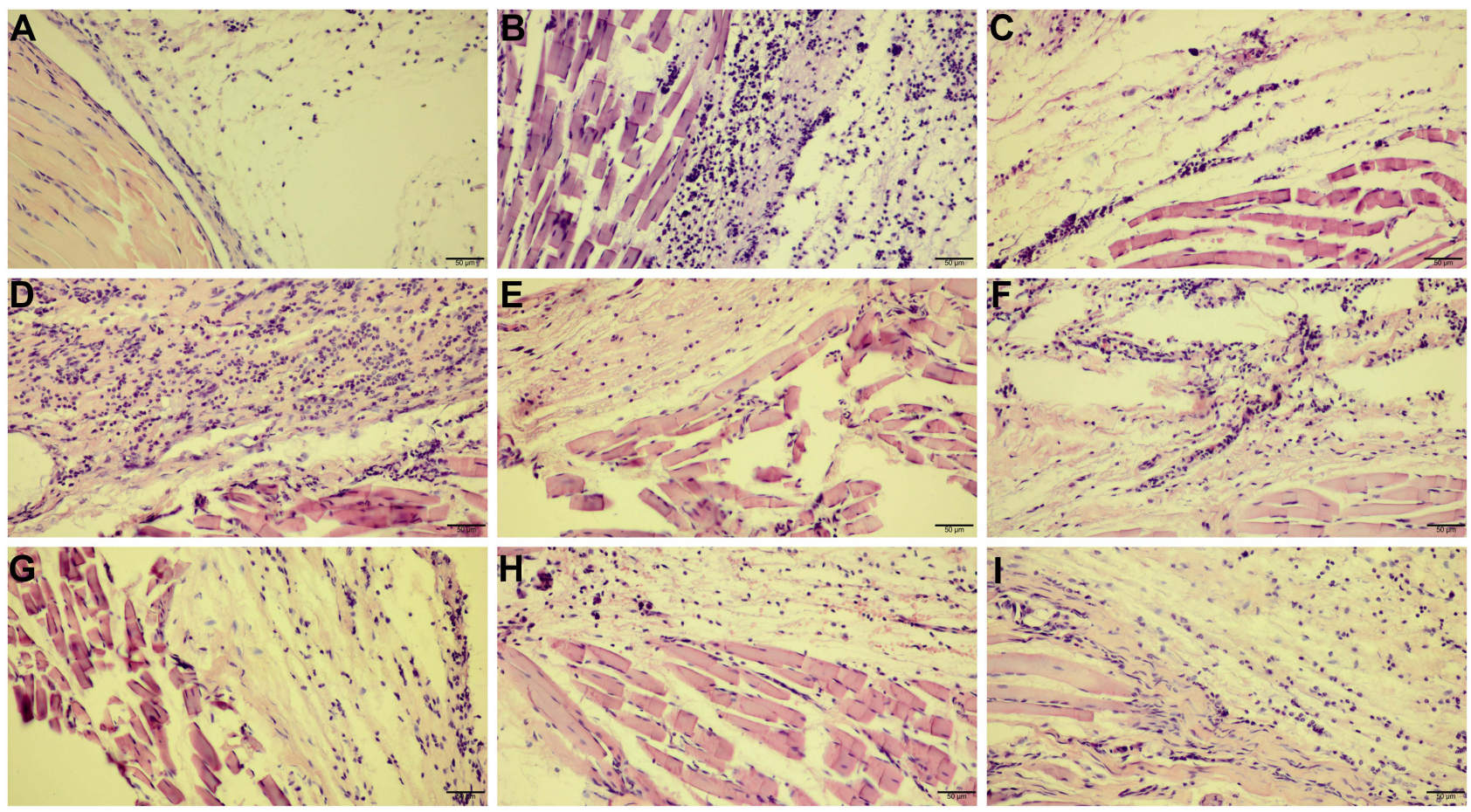

Figure 4 The photomicrographs of paw tissue after hematoxylin-eosin staining demonstrated that compounds I0b and I $\mathbf{3 b}$ diminished histological alterations induced by carrageenan injection. Indomethacin was used as a reference drug. Experimental groups: control group (A); carrageenan group (B); group receiving $10 \mathrm{mg} / \mathrm{kg}$ indomethacin (C); group receiving $5 \mathrm{mg} / \mathrm{kg}$ compound IOb (D); group receiving $10 \mathrm{mg} / \mathrm{kg}$ compound $\mathbf{I O b}$ (E); group receiving $20 \mathrm{mg} / \mathrm{kg}$ compound IOb (F); group receiving $5 \mathrm{mg} / \mathrm{kg}$ compound I3b (G); group receiving $10 \mathrm{mg} / \mathrm{kg}$ compound I3b $(\mathbf{H})$; group receiving $20 \mathrm{mg} / \mathrm{kg}$ compound I3b (I); magnification 200x. 


\section{The Effects of Pyrrolo[3,4- $d]$ Pyridazinone Derivatives on Carrageenan-Induced Paw Exudate}

To assess the composition of the inflammatory infiltration, a histopathological examination of the exudate of carrageenan-injected paws was performed. Table 1 shows the scoring of paw exudate samples. Carrageenan injection into the rats' right hind paws caused massive infiltration of inflammatory cells, significantly greater than in the control group $(p<0.001$; Figure 5 A and B). The cellular composition of the exudate comprised enormous number of polymorphonuclear leukocytes (neutrophils), lymphocytes, and few monocytes (Figure 5B). Pretreatment with compound 10b at the low or medium dose did not affect the composition of the exudate ( $p=N S$, Figure $5 \mathrm{D}$ and $\mathrm{E}$ ) and only at the high dose $(20 \mathrm{mg} / \mathrm{kg})$ reduced the number of inflammatory cells $(p<0.001$, Figure $5 F)$, while the administration of compound $\mathbf{1 3} \mathbf{b}$ at each studied dose reduced the number of inflammatory cells in comparison to the carrageenan group ( $p<0.05, p<0.001$, and $p<0.001$, respectively; Figure 5G-I). The effect of compound $\mathbf{1 3 b}$ at the medium dose was comparable to that provided by a reference drug, indomethacin $(\mathrm{p}=\mathrm{NS})$, and at the high dose was even greater than that of indomethacin $(\mathrm{p}<0.001$, Figure 5C, $\mathrm{H}$ and I).

\section{The Effects of Pyrrolo[3,4- $d]$ Pyridazinone Derivatives on the Liver and Kidney Function Parameters}

The serum activities of ALT and AST, as well as serum urea and creatinine concentrations, were measured to investigate the function of liver and kidney in rats pretreated with a single dose of pyrrolo[3,4- $d]$ pyridazinone derivatives. These results as mean \pm SEM are presented in Table 4 . Local administration of carrageenan did not significantly increase the serum ALT or AST activities and did not change the serum urea or creatinine levels in comparison to the control group $(p=N S)$. Intragastrical administration of either the $\mathbf{1 0 b}$ or $\mathbf{1 3 b}$ compound at all studied doses $(5,10$, or $20 \mathrm{mg} / \mathrm{kg}$ ) did not significantly alter the ALT or AST activities as well as the urea or creatinine levels in comparison to the control group ( $\mathrm{p}=\mathrm{NS})$, except for compound $\mathbf{1 0 b}$ given at the low dose $(5 \mathrm{mg} / \mathrm{kg})$ which significantly decreased the ALT activity ( $\mathrm{p}<0.05$ vs control). After a single $10 \mathrm{mg} / \mathrm{kg}$ intragastrical dose, indomethacin significantly increased the serum AST activity and serum urea concentration compared to the control group $(\mathrm{p}<0.05)$.
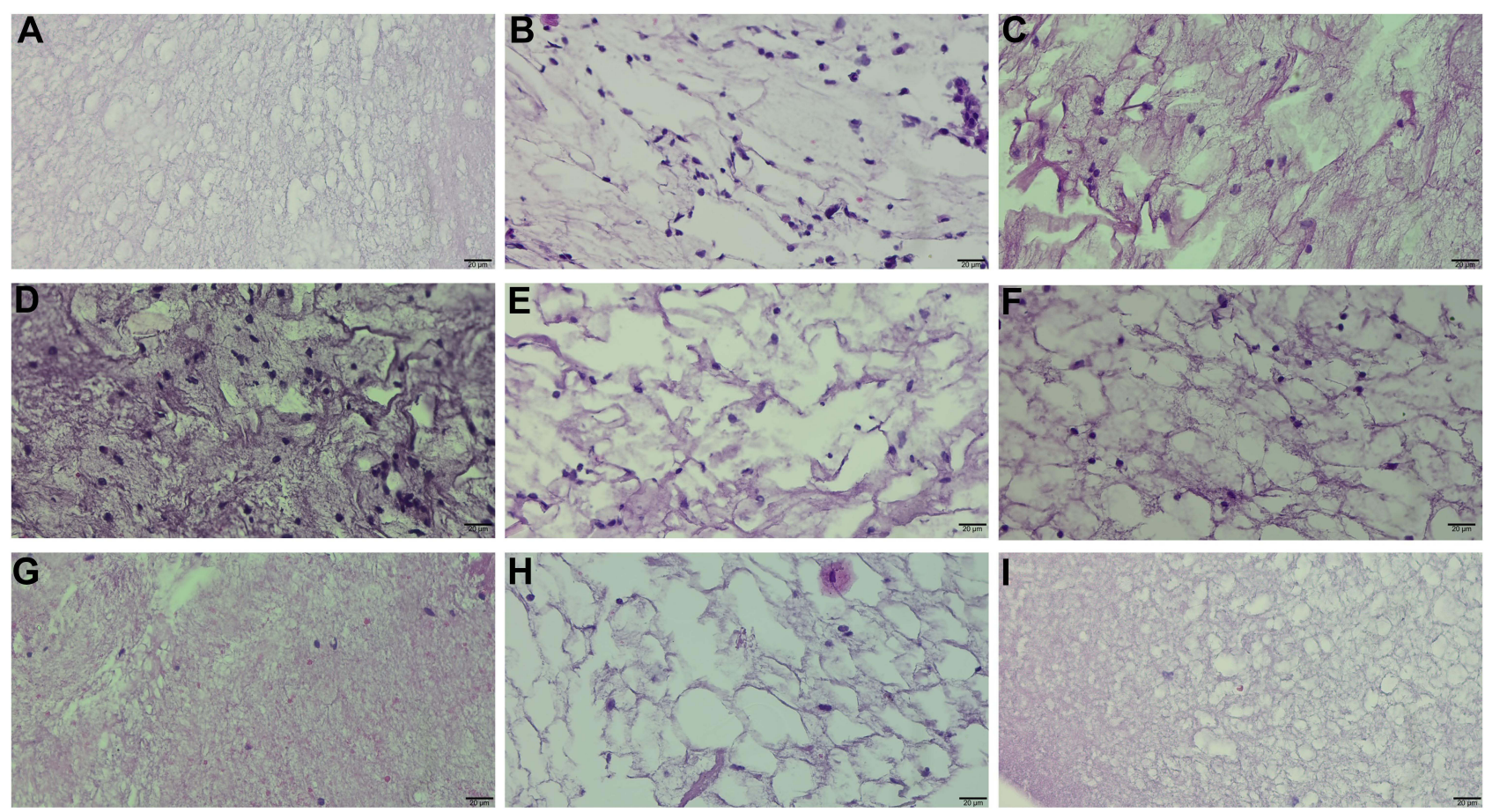

Figure 5 The photomicrographs of exudate of carrageenan-injected paw after hematoxylin-eosin staining demonstrated that the studied compounds reduced inflammatory cell infiltration. Indomethacin was used as a reference drug. Experimental groups: control group (A); carrageenan group (B); group receiving $10 \mathrm{mg} / \mathrm{kg}$ indomethacin (C); group receiving $5 \mathrm{mg} / \mathrm{kg}$ compound $\mathbf{I O b}(\mathbf{D})$; group receiving $10 \mathrm{mg} / \mathrm{kg}$ compound $\mathbf{I O b}(\mathbf{E})$; group receiving $20 \mathrm{mg} / \mathrm{kg}$ compound I Ob (F); group receiving $5 \mathrm{mg} / \mathrm{kg}$ compound I 3b (G); group receiving $10 \mathrm{mg} / \mathrm{kg}$ compound I3b (H); group receiving $20 \mathrm{mg} / \mathrm{kg}$ compound I3b (I); magnification 400×. 
Table 4 The Effects of Compounds $\mathbf{I O b}$ and $\mathbf{1 3 \mathbf { b }}$ on the Serum Biochemical Parameters in Rats. Indomethacin Was Used as a Reference Drug

\begin{tabular}{|l|c|c|c|c|}
\hline Group & ALT [UI/I] & AST [UI/I] & Urea [mg/dI] & Creatinine [mg/dl] \\
\hline C & $36.00 \pm 1.92$ & $118.75 \pm 3.97$ & $36.38 \pm 0.82$ & $0.21 \pm 0.02$ \\
Car & $37.00 \pm 2.24$ & $132.00 \pm 7.34$ & $39.63 \pm 0.94$ & $0.23 \pm 0.02$ \\
Ind & $37.63 \pm 2.54$ & $151.25 \pm 10.24 *$ & $44.63 \pm 3.83^{*}$ & $0.21 \pm 0.03$ \\
I0b-5 & $27.00 \pm 0.96 *$ & $115.13 \pm 2.95$ & $32.13 \pm 1.55$ & $0.25 \pm 0.02$ \\
I0b-10 & $28.50 \pm 0.63$ & $116.50 \pm 3.95$ & $35.13 \pm 1.37$ & $0.21 \pm 0.01$ \\
I0b-20 & $32.38 \pm 2.66$ & $129.75 \pm 4.05$ & $37.00 \pm 1.51$ & $0.21 \pm 0.02$ \\
I3b-5 & $28.88 \pm 1.09$ & $120.50 \pm 4.67$ & $30.13 \pm 0.90$ & $0.24 \pm 0.01$ \\
I3b-10 & $31.38 \pm 1.80$ & $124.38 \pm 3.50$ & $30.50 \pm 0.78$ & $0.24 \pm 0.01$ \\
I3b-20 & $31.75 \pm 1.18$ & $132.50 \pm 2.90$ & $34.25 \pm 1.11$ & $0.24 \pm 0.01$ \\
\hline
\end{tabular}

Notes: Experimental groups: C - control group; Car - carrageenan group; Ind - group receiving $10 \mathrm{mg} / \mathrm{kg}$ indomethacin; $10 \mathrm{~b}-5$, $10 \mathrm{~b}-10$, and I0b-20 - groups receiving, respectively, 5, I0, or $20 \mathrm{mg} / \mathrm{kg}$ of compound I Ob; I3b-5, I3b-10, and I3b-20 - groups receiving, respectively, 5, 10 , or $20 \mathrm{mg} / \mathrm{kg}$ of compound I3b. Data are presented as mean values $\pm \operatorname{SEM}(n=12)$. ${ }^{*}<0.05$ vs the control group.

\section{The Effects of Pyrrolo[3,4-d]Pyridazinone Derivatives on Gastric Mucosa in Macro- and Microscopic Assessment}

Macro- and microscopic evaluation was carried out to characterize the gastric safety profile of the compounds studied. The presence and severity of macroscopically visible mucosal lesions (petechiae, hemorrhagic erosions) were scored as indicators of ulcerogenic activity (Table 2). There was no injury to gastric mucosa in the control or carrageenan group (Figure 6A and B). The findings of these ulcerogenic liability studies demonstrated that novel derivatives in all studied doses caused negligible mucosal lesions as compared to the control group ( $\mathrm{p}=\mathrm{NS}$, Figure $6 \mathrm{D}-\mathrm{G})$, whereas indomethacin at a dose of $10 \mathrm{mg} / \mathrm{kg}$ caused significant mucosal injuries ranging from hyperemia to hemorrhagic lesions covered with coagulated blood ( $<0.001$; Figure 6C). The macroscopic changes were reflected in the microscopic appraisal (Table 2). The stomach tissue of rats pretreated with the studied compounds as well as control rats showed no histopathological changes with intact mucosa, submucosa, and musculosa ( $p=$ NS; Figure 7A, F, G, H and I). Subplantar administration of carrageenan caused no significant injury to
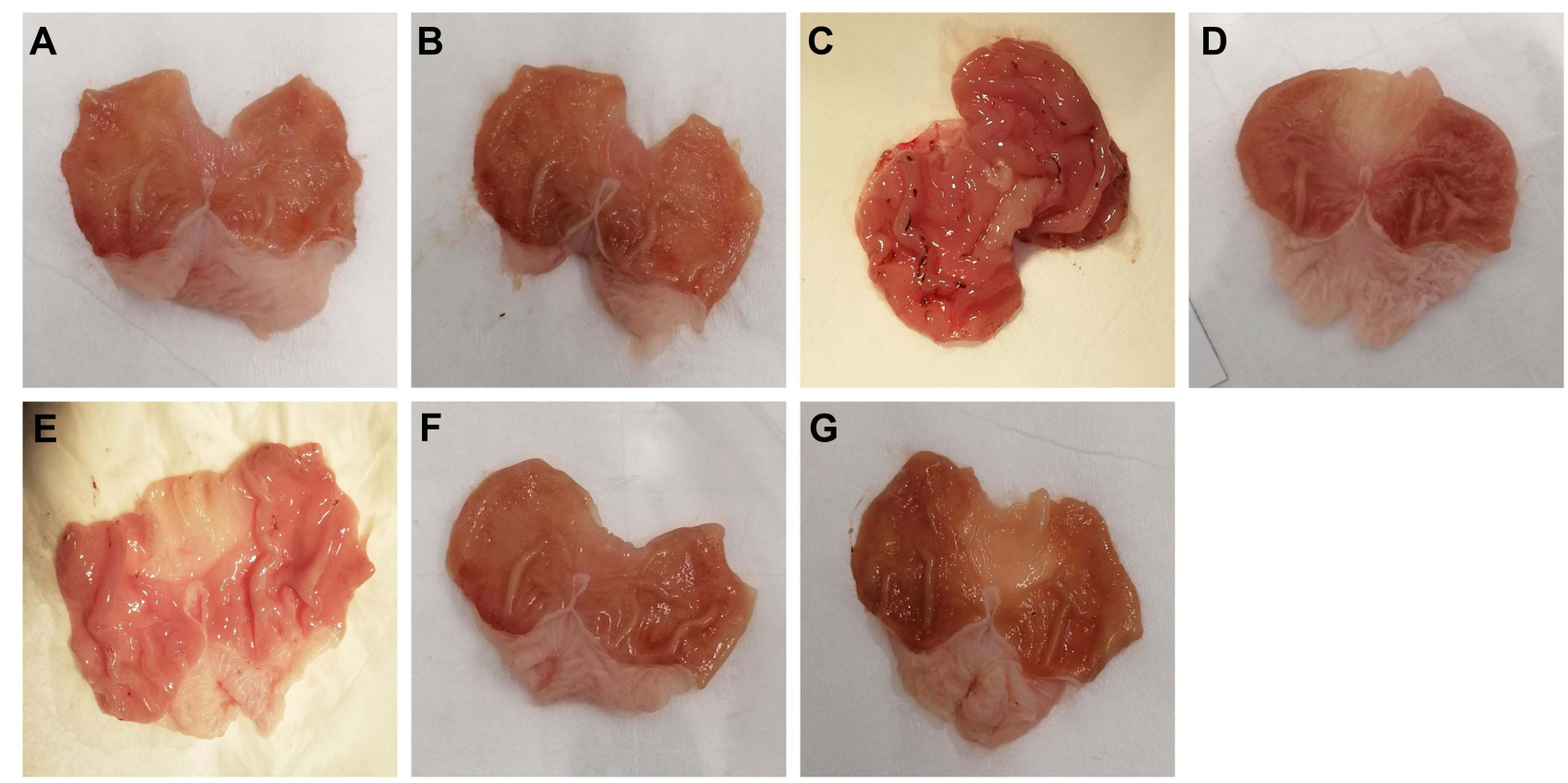

Figure 6 The macroscopic appearance of the gastric mucosa revealed that the studied compounds caused negligible mucosal lesions. Indomethacin was used as a reference drug. Experimental groups: control group (A); carrageenan group (B); group receiving $10 \mathrm{mg} / \mathrm{kg}$ indomethacin (C); group receiving $10 \mathrm{mg} / \mathrm{kg}$ compound I0b (D); group receiving $20 \mathrm{mg} / \mathrm{kg}$ compound $\mathbf{1 0 b}(\mathbf{E})$; group receiving $10 \mathrm{mg} / \mathrm{kg}$ compound $\mathbf{I 3 b}(\mathbf{F})$; group receiving $20 \mathrm{mg} / \mathrm{kg}$ compound $\mathbf{I 3 b}(\mathbf{G})$. 

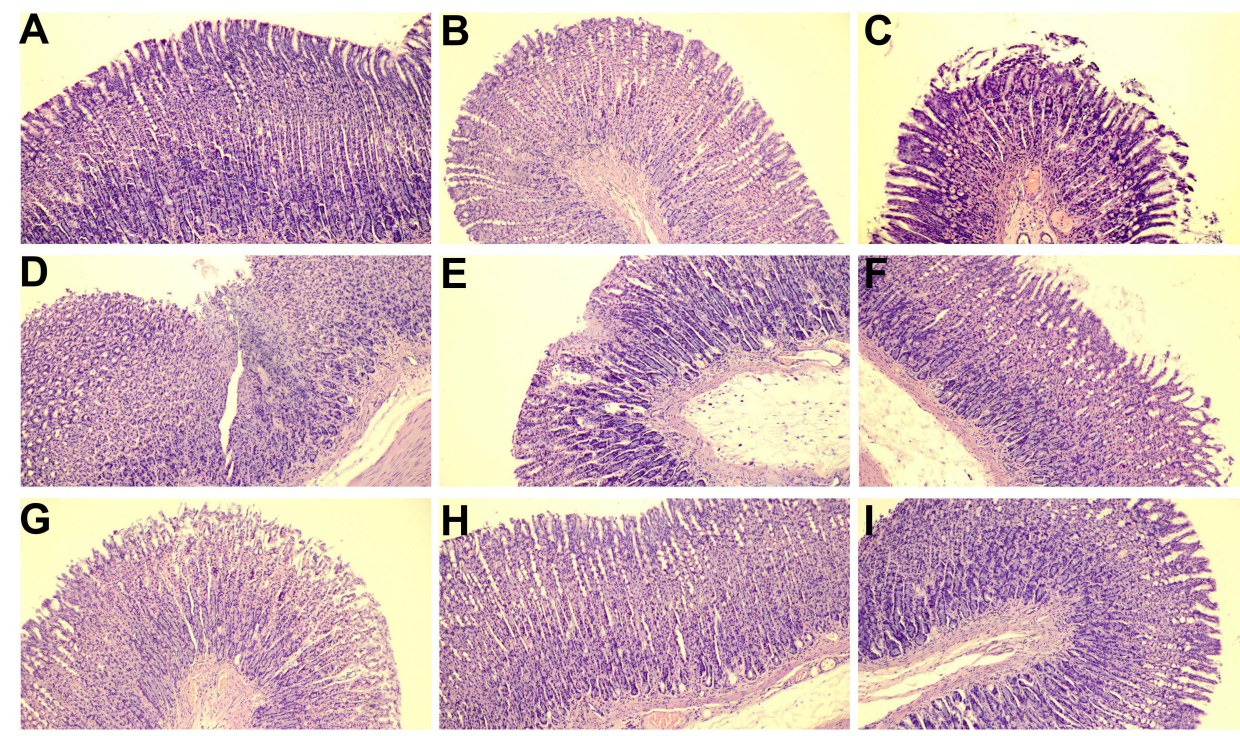

Figure 7 The microphotographs of stomach tissue after hematoxylin-eosin staining revealed that the studied compounds neither altered the normal stomach tissue architecture nor induced ulcerations. Indomethacin was used as a reference drug. Experimental groups: control group (A); carrageenan group (B); group receiving $10 \mathrm{mg} / \mathrm{kg}$ indomethacin (C-E); group receiving $10 \mathrm{mg} / \mathrm{kg}$ compound IOb $(\mathbf{F})$; group receiving $20 \mathrm{mg} / \mathrm{kg}$ compound $\mathbf{1 0 b}(\mathbf{G}) ;$ group receiving $10 \mathrm{mg} / \mathrm{kg}$ compound $\mathbf{I} \mathbf{3 b}(\mathbf{H})$; group receiving $20 \mathrm{mg} / \mathrm{kg}$ compound I3b (I); magnification I00x.

the stomach tissue in microscopic analysis $(\mathrm{p}=\mathrm{NS}$; Figure 7B). Meanwhile, following indomethacin administration, the stomach tissue was characterized by appreciable damage to the protective mucosal layer with local thinning of the mucosa and damage to the superficial layer with some visible crater-like cavities, focal necrosis of gastric mucosa, submucosal edema, and congestion of mucosal and submucosal blood vessels ( $p<0.001$; Figure 7C-E).

\section{Multi-Criteria Decision Analysis}

The results obtained from each bioassay (carrageenaninduced paw edema test, ELISA, microscopic assessment of paw tissue and paw exudate, assessment of serum biochemical parameters, and macro- and microscopic assessment of gastric mucosa) were analyzed by MCDA to compare the studied pharmacological and toxicological properties, as well as the risks and benefits of pretreatment with the new compounds. The MCDA results (Figure 8) indicated that the most favorable profile of action, ie, the strongest anti-inflammatory effect with the lowest risk of hepatic, renal, and gastric toxicity, was found for compound 13b at a dose of $20 \mathrm{mg} / \mathrm{kg}$. Moreover, compounds 10b and 13b exerted a more favorable effect than indomethacin when administered at both the same dose as indomethacin $(10 \mathrm{mg} / \mathrm{kg})$ and at a higher dose than indomethacin $(20 \mathrm{mg} / \mathrm{kg})$. In the studied dose range, compound 13b exerted a more favorable effect than compound $\mathbf{1 0 b}$.

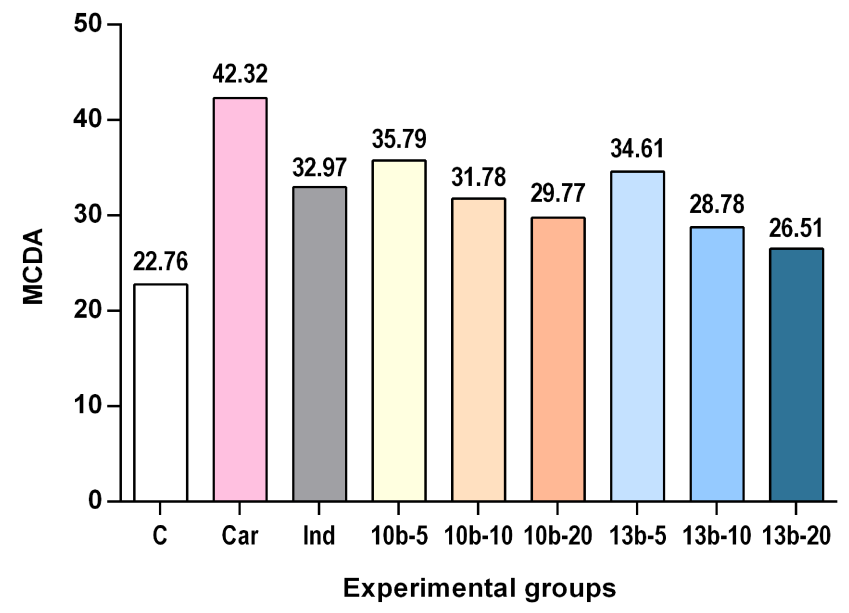

Figure 8 Multi-criteria decision analysis (MCDA) of the anti-inflammatory effect and hepatic, renal, and gastric toxicity of the studied compounds $\mathbf{I O b}$ and $\mathbf{I} \mathbf{3} \mathbf{b}$.

\section{Discussion}

The word carrageenan, derived from the Irish word "carraigin" meaning Irish moss (Chondrus crispus L.), refers not only to this species of algae but also to its mucopolysaccharide extract, discovered by the British pharmacist Stanford in $1862 .{ }^{26}$ This mucopolysaccharide extract consists of several types of carrageenans, including lambda carrageenan, which is used in an experimental model of acute inflammation as a potent inflammatory-triggering agent. ${ }^{26,27}$ Carrageenaninduced inflammation (also called carrageenan-induced paw edema), originally described by Winter, $^{22}$ is a valuable tool widely used to assess the potential anti- 
inflammatory activity of any novel substance. ${ }^{27-29}$ It is noteworthy that inhibition of carrageenan-induced inflammation is highly predictive of anti-inflammatory drug activity in human inflammatory disorders. Moreover, the doses of anti-inflammatory agents in this model correlate well with effective doses in patients. ${ }^{30,31}$ Thus, this model has a vital role in novel drug development.

Carrageenan injection into the rat hind paw elicits an inflammatory response in a biphasic manner. The first phase ( $0-1 \mathrm{~h}$ after injection) mediated by histamine, serotonin, and bradykinin is followed by a second phase (2-6 $\mathrm{h}$ after injection), which is attributed to infiltration of polymorphonuclear leukocytes, mainly neutrophils, and production of prostaglandins (PGs), especially $\mathrm{PGE}_{2}$ and various proinflammatory cytokines such as IL-1, IL-6, and TNF- $\alpha .^{32,33}$ The first phase causes local vasodilatation and rapid increase in the vascular permeability with consequent edema formation, and the second phase enables edema maintenance due to PGs' potent vasoactive action and their ability to recruit inflammatory cells. Therefore, this animal model, as it happened in this study, displays hallmark signs of acute inflammation (redness, edema, heat, pain, loss of function), which develop instantaneously following subplantar injection of carrageenan solution into the rat hind paw. In carrageenan-induced inflammation, the inflammatory response is quantified by an increase in paw volume (paw edema), which can be modulated by inhibitors of specific molecules within the inflammatory cascade. ${ }^{27}$ In the present study, the inflammatory response indicated by the paw edema lasted up to $6 \mathrm{~h}$ following carrageenan injection. Both studied compounds given at a dose of 10 or $20 \mathrm{mg} / \mathrm{kg}$ partly inhibited paw edema starting at $2 \mathrm{~h}$ after carrageenan injection, and this effect peaked at $3 \mathrm{~h}$ and continued for up to $6 \mathrm{~h}$. At the low dose $(5 \mathrm{mg} / \mathrm{kg})$, compound $\mathbf{1 0 b}$ partly suppressed paw edema only at $2 \mathrm{~h}$, while compound $\mathbf{1 3 b}$ at 2, 3, and $6 \mathrm{~h}$ after carrageenan injection. Since novel pyrrolo $[3,4-d]$ pyridazinone derivatives suppressed the second phase of carrageenan-induced paw edema, it can be assumed that they exert an anti-inflammatory effect by inhibiting the release of prostaglandins and proinflammatory cytokines and reducing inflammatory cell infiltration. The action of compounds $\mathbf{1 0 b}$ and $\mathbf{1 3 b}$ given at the high dose was comparable to the effect provided by indomethacin, which also decreased edema at 2, 3, and $6 \mathrm{~h}$ with maximal inhibitory effect at $3 \mathrm{~h}$. At $3 \mathrm{~h}$, indomethacin completely reversed the increase in paw volume, whereas at $6 \mathrm{~h}$ it reversed the increase only partly. This diminution of inhibitory effect at $6 \mathrm{~h}$ can be explained by the fact that COX-2 expression increases after $3 \mathrm{~h}$ following carrageenan injection and reaches maximal expression at $6 \mathrm{~h}^{34}$ In our previous work, we demonstrated that new pyrrolo $[3,4-d]$ pyridazinone derivatives strongly inhibit cyclooxygenase with a better affinity towards COX-2 isoform, and some of them, including compound $\mathbf{1 3 b}$, act as selective COX-2 inhibitors. ${ }^{12}$ Thus, compound $\mathbf{1 0 b}$ as a preferential COX-2 inhibitor and indomethacin as COX-1/COX-2 inhibitor showed a greater diminution in the inhibitory effect than compound $\mathbf{1 3 b}$, a selective COX-2 inhibitor, whose diminution of inhibitory effect at $6 \mathrm{~h}$ was the lowest. Neither the new compounds nor indomethacin inhibited the early phase of edema formation. This is consistent with findings reported by other authors who have shown that the second phase of edema formation is sensitive to non-steroidal anti-inflammatory agents, including indomethacin. ${ }^{28,35}$

Although many components have been implicated in the course of the inflammatory response, a lot of studies placed prostanoids synthesis, especially $\mathrm{PGE}_{2}$, as a crucial element and important link in the chain of events leading to the carrageenan-invoked inflammatory response. ${ }^{28,36,37}$ $\mathrm{PGE}_{2}$ is well established as a mediator of acute inflammation, which regulates multiple aspects of inflammation and multiple functions of different immune cells. $\mathrm{PGE}_{2}$ can promote local vasodilatation, fluid and protein extravasation, and the local attraction of neutrophils and macrophages from the bloodstream to the site of tissue injury and their activation, thereby leading to general symptoms of inflammation. ${ }^{7}$ Nevertheless, this molecule is also involved in the detrimental transition from acute to chronic inflammation and its maintenance, which may lead to chronic inflammatory diseases. $\mathrm{PGE}_{2}$ can convert a shortterm inflammatory response into a long-term process, primarily by enhancing proinflammatory cytokine release cascade, contributing to the differentiation and activation of Th1 and Th17 cells, and contributing to aberrant tissue remodeling. $^{38,39}$ Thus, normalization of the increased $\mathrm{PGE}_{2}$ levels may be crucial not only in the removal of symptoms of acute inflammation but also in preventing acute inflammation from becoming a chronic inflammatory state. As aforementioned, a decrease in the $\mathrm{PGE}_{2}$ level may contribute to the attenuation of the second phase of carrageenan-induced inflammation. In the current study, we have indicated that pretreatment with both novel 1,3,4-oxadiazole derivatives of pyrrolo[3,4- $d]$ pyridazinone at the medium or high dose counteracted the increased 
$\mathrm{PGE}_{2}$ level in paw tissue compared to the group of carrageenan-injected rats, and this action was comparable to that of indomethacin. This is in agreement with the results described by Ozyazici et al, showing that some other 1,3,4-oxadiazole derivatives based on compounds with known anti-inflammatory action reduced $\mathrm{PGE}_{2}$ production in LPS-stimulated RAW 264.7 cells similarly to indomethacin. $^{40}$ It is known that $\mathrm{PGE}_{2}$ constitutes a potent sensitizing agent able to modulate the nociceptive pathway via peripheral and central mechanisms and is regarded as an essential mediator of hyperalgesia. ${ }^{7}$ In our previous study, we found that at the medium and high doses, compound $\mathbf{1 3 b}$, but not $\mathbf{1 0 b}$, has an antinociceptive effect, which may be due to the inhibition of nociceptor sensitization by decreasing the $\mathrm{PGE}_{2}$ level. ${ }^{18}$ This discrepancy between the action of compound $\mathbf{1 0 b}$ on the $\mathrm{PGE}_{2}$ level reported in our earlier paper ${ }^{18}$ and the current study may result from the fact that while both cyclooxygenase isoforms are involved in the inflammatory response, COX2 is the prevalent isoform involved in the nociceptor sensitization and hyperalgesia. ${ }^{7}$

In addition to prostaglandins, proinflammatory cytokines are the other molecules contributing to the development of edema during the second and subsequent hours after injection of carrageenan. ${ }^{33}$ One of the most important cytokines that govern the development and maintenance of inflammation is TNF- $\alpha .^{41}$ TNF- $\alpha$ can activate macrophages and upregulate other proinflammatory cytokines and endothelial adhesion molecules, thus promoting the adhesion of neutrophils and lymphocytes to endothelial cells and their extravasation. ${ }^{2,42,43}$ Moreover, TNF- $\alpha$ contributes to tissue damage and multiorgan failure and is considered an important mediator of the development of various chronic inflammatory diseases. ${ }^{42}$ In the current study, inhibition of the inflammatory response by the new compounds was accompanied by a decrease in the TNF- $\alpha$ level. Compound $\mathbf{1 0 b}$ at the medium or high dose partly reversed alteration in TNF- $\alpha$ tissue concentration as compared with carrageenan-injected rats, while compound 13b at the same doses completely counteracted the increased TNF- $\alpha$ level in paw tissue. It is noteworthy that the action of compound 13b given at the high dose was even greater than the effect of indomethacin. Moreover, we found that, contrary to compound $\mathbf{1 0 b}$ and indomethacin, the suppressive effect of compound $\mathbf{1 3 b}$ on TNF- $\alpha$ release was greater than its effect on $\mathrm{PGE}_{2}$, which supports the possibility that compound $\mathbf{1 3 b}$ has a greater inhibitory effect on proinflammatory cytokines release than either compound $\mathbf{1 0 b}$ or indomethacin. Our results are in line with previous findings showing that 1,3,4-oxadiazole derivatives can decrease the tissue TNF- $\alpha$ level in the carrageenan-induced paw edema test. ${ }^{44}$ Likewise, Mogilski et $\mathrm{al}^{11}$ reported that pyrrolo[3,4- $\left.d\right]$ pyridazinone derivatives decreased the TNF- $\alpha$ level in LPS-activated RAW264.7 macrophage, a cell line frequently used for the screening of anti-inflammatory activity of new compounds. $^{42}$

Local neutrophil infiltration and activation also contribute to the inflammation caused by tissue damage, ${ }^{45}$ including carrageenan-induced inflammation. ${ }^{42}$ After carrageenan injection, neutrophils are both the first and the primary cells recruited to the site of inflammation; their infiltration can be identified by measuring the levels of myeloperoxidase, one of the major enzymes released from activated neutrophils. $^{5,42}$ Interestingly, accumulating evidence indicates that MPO serves not only as an index of neutrophil infiltration into inflamed tissues but also displays cytokine-like properties. ${ }^{5}$ Proinflammatory properties of MPO are independent of its enzymatic and bactericidal activity and occur as a result of its ability to interact with an integrin Mac-1 (CD11b/CD18). The linking of MPO to Mac-1 leads to the modulation of intracellular neutrophil signaling pathways and thereby to neutrophil activation and extravasation. Indeed, MPO evokes a neutrophil response similar to those triggered by proinflammatory cytokines, especially TNF- $\alpha .^{5}$ Moreover, MPO may increase Mac-1 expression, cause further MPO release from neutrophils, and delay their intrinsic apoptosis. ${ }^{46,47}$ This MPO-dependent feedforward loop amplifies the response of neutrophils, thereby prolonging inflammation, causing local tissue damage, and leading to chronic inflammatory conditions. ${ }^{46}$ As such, the reduction of the MPO level is regarded as another crucial condition to alleviate the second phase of carrageenaninduced inflammatory response. ${ }^{48}$ In the present study, we indicated that compared to the carrageenan-injected rats, pretreatment with compound $\mathbf{1 3 b}$ at all doses tested counteracted the increased MPO level in paw tissue, and this effect was similar to that provided by indomethacin. The achieved results concur well with our earlier findings that pretreatment with compound $\mathbf{1 3 b}$, but not $\mathbf{1 0 b}$, at the doses of 10 and $20 \mathrm{mg} / \mathrm{kg}$ decreased the MPO level in the inflammatory phase of the formalin test. ${ }^{18}$ Moreover, Cidade et $\mathrm{al}^{44}$ demonstrated that some other 1,3,4-oxadiazole derivatives decreased the MPO level in the carrageenan-induced paw edema test. 
The action of the above-mentioned inflammatory mediators, $\mathrm{PGE}_{2}$, TNF- $\alpha$, and MPO, results in plasma exudation and migration of peripheral blood leukocytes into the injured area. ${ }^{2,5,7,42}$ It has been pointed out that after the injection of carrageenan, the total number of exudate leukocytes increases with time, and over $96 \%$ of exudate leukocytes are neutrophils. ${ }^{49}$ Palaska et $\mathrm{al}^{50}$ found that various 1,3,4-oxadiazole-2-thione derivatives reduced the total number of exudate leukocytes. In our study, histological evaluation of paw exudates showed that subplantar carrageenan injection caused massive infiltration of inflammatory cells, including neutrophils, lymphocytes, and monocytes. Compared to the carrageenan group, pretreatment with compound $\mathbf{1 0 b}$ at the high dose or with compound 13b at each studied dose reduced the influx of all inflammatory cells into the inflamed tissue. The effect of compound 13b at the medium dose was comparable to that elicited by the reference drug, indomethacin, and at the high dose was even greater than that of indomethacin. The more pronounced effect exhibited by compound $\mathbf{1 3 b}$ could be explained by the fact that, contrary to compound 10b, compound 13b decreased the MPO level, leading to the interruption of the MPO-dependent loop with a consequent reduction in neutrophil activation and migration into the inflamed tissue.

The histological analysis of the paw tissue indicated that carrageenan-induced inflammation is linked to intense edema characterized by increased infiltration of inflammatory cells and loss of normal muscle architecture in the inflamed paw tissue, consistent with the findings reported by other authors. ${ }^{51}$ The results obtained in our study show that both compounds at a dose of 10 or $20 \mathrm{mg} / \mathrm{kg}$ decreased the edema formation and the elevated level of cellular infiltration in rat paw tissue induced by carrageenan injection. Histopathology of the paw tissue also revealed that pretreatment with compound $\mathbf{1 3 b}$ at the high dose resulted in a nearly normal paw tissue architecture with minimal inflammation and an effect comparable to that of indomethacin. These data support the results of paw edema measurement, changes in biochemical parameters, and histology of exudates and verify and confirm the anti-inflammatory effect of the studied compounds against acute inflammation. To our best knowledge, our study is the first to evaluate the effect of pyrrolo[3,4- $d]$ pyridazinone derivatives on inflammatory cell infiltration and tissue alterations induced by carrageenan injection in experimental inflammation in rats, indicating that pretreatment with these new compounds prevented not only the increase in inflammatory cell migration into the inflamed tissue but also morphological alterations.

The liver and kidneys are important essential organs for drug metabolism, storage, and excretion, making them particularly vulnerable to drug-related damage. Moreover, inhibition of COX-1 and COX-2 derived prostaglandins by most commonly used anti-inflammatory drugs, ie, NSAIDs, may cause serious adverse effects, eg, gastrointestinal irritation, erosions, ulceration, and bleeding as well as glomerular filtration impairment, and sodium and water retention. ${ }^{9,52,53}$ It is noteworthy that it is not only the NSAIDs' mechanism of action but also their chemical structure that may contribute to their toxicity. ${ }^{9}$ Typical NSAIDs consist of an acidic moiety linked to an aromatic functional group. The majority of NSAIDs contain a free carboxyl group as an acidic moiety, which may elicit gastric mucosal damage by local irritation in the ion trapping mechanism and through a reduction of mucosal surface hydrophobicity. ${ }^{54}$ The chemical structure of NSAIDs may also contribute to their hepatotoxicity. Although the exact mechanism of NSAIDs' hepatotoxicity is not completely understood, it is assumed that an acidic group of NSAIDs or reactive adducts of NSAID metabolites may interact with host proteins and lead to cellular injury in susceptible patients. ${ }^{55}$ Considering that the tested compounds act by inhibiting the COX pathway, it seems justified to make a preliminary assessment of the effect of pretreatment with a single dose of these new compounds on the markers of toxicity to the liver, kidneys, and gastric mucosa. An increase in serum ALT and AST activities may be interpreted as a result of hepatocyte injury or changes in their membrane permeability, indicating severe hepatocellular damage. Additionally, ALT and AST are useful indicators for identifying inflammation or necrosis of the liver. ${ }^{56}$ Thereby, serum ALT and AST activity are considered predictors of possible hepatic toxicity. ${ }^{57}$ In some studies, elevated levels of ALT have been observed already several hours after administration of a single dose of NSAID. ${ }^{58,59}$ Physiologically, urea and creatinine are filtered out of the blood by the kidneys. In renal disorders, when the kidneys are unable to excrete urea and creatinine properly, they are retained in the blood, and their levels become elevated. ${ }^{56}$ Urea and creatinine levels are thus regarded as biomarkers predicting possible renal toxicity. ${ }^{60}$ The results of the present study revealed that, unlike indomethacin, pretreatment with compound 10b or 13b - even at a high dose - did not alter ALT and AST activities or urea and creatinine levels compared 
to the control rats. This suggests that these new compounds are not hepato- or nephrotoxic at the doses tested. As far as we know, this work is the first to evaluate the effect of 1,3,4-oxadiazole derivatives on hepatic and renal toxicity markers. It cannot be excluded that the replacement of the free carboxyl group with 1,3,4-oxadiazole2-thione may contribute to reducing the hepatotoxicity of the designed compounds. Similarly, in contrast to indomethacin, which caused mucosal injury ranging from hyperemia to hemorrhagic lesions, both studied compounds given in all studied doses caused negligible macroscopic mucosal lesions and no histopathological changes, with the mucosa, submucosa, and musculosa remaining intact. In the previously published paper, ${ }^{18}$ the same compounds $-\mathbf{1 0 b}$ and $\mathbf{1 3 b}$ - were superior in gastric safety profile to indomethacin in macro- and microscopic evaluation in mice. This implies greater safety of our newly synthesized compounds on the gastric mucosa. Our results corroborated with other authors' findings showing that a 1,3,4-oxadiazole-2-thione ring incorporated into a given structure results in lower gastrotoxicity. ${ }^{13-15}$ Presumably, the conversion of the free carboxyl group to the fivemembered 1,3,4-oxadiazole-2-thione, bioisosteric ring results in no local irritation and increases selectivity to COX-2, thereby reducing gastrotoxicity. More detailed research is needed to evaluate the safety profile of these two new compounds after repeated administration since many anti-inflammatory agents are used for long-term treatment.

\section{Conclusion}

The results provided herein point to the conclusion that the novel pyrrolo[3,4- $d]$ pyridazinone derivatives, $\mathbf{1 0 b}$ and 13b, exert anti-inflammatory activity, and their mechanism of action might be related to the decrease of the $\mathrm{PGE}_{2}$, TNF- $\alpha$, and MPO levels and the reduction of inflammatory cell infiltration in inflamed tissues. Even though the new pyrrolo[3,4- $d]$ pyridazinone derivatives are slightly less effective than the reference drug indomethacin, they do not cause gastric mucosal injuries and hepato-, or nephrotoxicity like it does, which is their indisputable advantage. Based on the findings of multi-criteria decision analysis, it may be inferred that the new compounds, $\mathbf{1 0 b}$ and $\mathbf{1 3 b}$, have a more favorable benefit-risk profile than indomethacin. Compound $\mathbf{1 3 b}$ at the high dose $(20 \mathrm{mg} / \mathrm{kg})$ reveals the most favorable benefit-risk profile among all doses of the studied compounds. Accordingly, the application of compound 13b might be considered a promising therapeutic strategy that could be useful in the management of various inflammatory diseases. Additionally, the results achieved in this study prove that the new 1,3,4-oxadiazole derivatives of pyrrolo[3,4- $d]$ pyridazinone represent a promising template for further development towards potent and safe anti-inflammatory agents. Nevertheless, further investigations are needed to confirm and clarify the mechanism involved in the antiinflammatory effect of the compounds examined.

\section{Acknowledgments}

The authors are grateful to Paulina Jawień and Joanna Kwiatkowska for support with experiments conduction. We are also thankful to Kamila Czyszczoń, and Maja Lipińska for their assistance with animal maintenance and care.

\section{Author Contributions}

All authors contributed to data analysis, drafting or revising the article, have agreed on the journal to which the article will be submitted, gave final approval of the version to be published, and agree to be accountable for all aspects of the work.

\section{Disclosure}

The authors declare no conflicts of interest in this work.

\section{References}

1. Goldstein DS. How does homeostasis happen? Integrative physiological, systems biological, and evolutionary perspectives. Am J Physiol Regul Integr Comp Physiol. 2019;316(4):R301-R317. doi:10.1152/ ajpregu.00396.2018

2. Medzhitov R. Origin and physiological roles of inflammation. Nature. 2008;454(7203):428-435. doi:10.1038/nature07201

3. Chen Z, Ni W, Yang C, et al. Therapeutic effect of Amomum villosum on inflammatory bowel disease in rats. Front Pharmacol. 2018;9:639. doi:10.3389/fphar.2018.00639

4. Gilroy D, De Maeyer R. New insights into the resolution of inflammation. Semin Immunol. 2015;27(3):161-168. doi:10.1016/j. smim.2015.05.003

5. Lau D, Mollnau H, Eiserich JP, et al. Myeloperoxidase mediates neutrophil activation by association with $\mathrm{CD} 11 \mathrm{~b} / \mathrm{CD} 18$ integrins. Proc Natl Acad Sci U S A. 2005;102(2):431-436. doi:10.1073/ pnas.0405193102

6. Haegens A, Heeringa P, van Suylen RJ, et al. Myeloperoxidase deficiency attenuates lipopolysaccharide-induced acute lung inflammation and subsequent cytokine and chemokine production. J Immunol. 2009;182(12):7990-7996. doi:10.4049/jimmunol.0800377

7. Leuti A, Fazio D, Fava M, Piccoli A, Oddi S, Maccarrone M. Bioactive lipids, inflammation and chronic diseases. Adv Drug Deliv Rev. 2020;159:133-169.

8. Ferrero-Miliani L, Nielsen OH, Andersen PS, Girardin SE. Chronic inflammation: importance of NOD2 and NALP3 in interleukin-1beta generation. Clin Exp Immunol. 2007;147(2):227-235. 
9. Bindu S, Mazumder S, Bandyopadhyay U. Non-steroidal anti-inflammatory drugs (NSAIDs) and organ damage: a current perspective. Biochem Pharmacol. 2020;180:114147. doi:10.1016/j. bcp. 2020.114147

10. Malinka W, Redzicka A, Lozach O. New derivatives of pyrrolo [3,4-d]pyridazinone and their anticancer effects. Farmaco. 2004;59 (6):457-462. doi:10.1016/j.farmac.2004.03.002

11. Mogilski S, Kubacka M, Redzicka A, et al. Antinociceptive, anti-inflammatory and smooth muscle relaxant activities of the pyrrolo[3,4- $d$ ]pyridazinone derivatives: possible mechanisms of action. Pharmacol Biochem Behav. 2015;133:99-110. doi:10.1016/j. pbb.2015.03.019

12. Szczukowski Ł, Redzicka A, Wiatrak B, et al. Design, synthesis, biological evaluation and in silico studies of novel pyrrolo[3,4- $d$ ] pyridazinone derivatives with promising anti-inflammatory and antioxidant activity. Bioorg Chem. 2020;102:104035. doi:10.1016/j. bioorg.2020.104035

13. Manjunatha K, Poojary B, Lobo PL, Fernandes J, Kumari NS. Synthesis and biological evaluation of some 1,3,4-oxadiazole derivatives. Eur J Med Chem. 2010;45(11):5225-5233. doi:10.1016/ j.ejmech.2010.08.039

14. Palkar MB, Singhai AS, Ronad PM, et al. Synthesis, pharmacological screening and in silico studies of new class of diclofenac analogues as a promising anti-inflammatory agents. Bioorg Med Chem. 2014;22 (10):2855-2866. doi:10.1016/j.bmc.2014.03.043

15. Koksal M, Ozkan-Dagliyan I, Ozyazici T, et al. Some novel mannich bases of 5-(3,4-dichlorophenyl)-1,3,4-oxadiazole-2(3 H)-one and their anti-inflammatory activity. Arch Pharm. 2017;350(9):1700153. doi:10.1002/ardp.201700153

16. Avci A, Taşci H, Kandemir Ü, Can ÖD, Gökhan-Kelekçi N, Tozkoparan B. Synthesis, characterization, and in vivo pharmacological evaluation of novel mannich bases derived from 1,2,4-triazole containing a naproxen moiety. Bioorg Chem. 2020;100:103892. doi:10.1016/j.bioorg.2020.103892

17. Wakulik K, Wiatrak B, Szczukowski Ł, et al. Effect of novel pyrrolo $[3,4-d]$ pyridazinone derivatives on lipopolysaccharide-induced neuroinflammation. Int J Mol Sci. 2020;21(7):2575. doi:10.3390/ ijms 21072575

18. Szandruk-Bender M, Wiatrak B, Szczukowski $€$, et al. Novel 1,3,4-oxadiazole derivatives of pyrrolo[3,4- $d$ ]pyridazinone exert antinociceptive activity in the tail-flick and formalin test in rodents and reveal reduced gastrotoxicity. Int J Mol Sci. 2020;21(24):9685. doi:10.3390/ijms21249685

19. Basbaum AI, Bautista DM, Scherrer G, Julius D. Cellular and molecular mechanisms of pain. Cell. 2009;139(2):267-284. doi:10.1016/j. cell.2009.09.028

20. Florentino IF, Silva DPB, Galdino PM, et al. Antinociceptive and anti-inflammatory effects of Memora nodosa and allantoin in mice. J Ethnopharmacol. 2016;186:298-304. doi:10.1016/j.jep.2016.04.010

21. Malinka W, Redzicka A, Jastrzębska-Więsek M, et al. Derivatives of pyrrolo[3,4-d]pyridazinone, a new class of analgesic agents. Eur J Med Chem. 2011;46(10):4992-4999. doi:10.1016/j.ejmech.2011.08.006

22. Winter CA, Risley EA, Nuss GW. Carrageenin-induced edema in hind paw of the rat as an assay for antiinflammatory drugs. Proc Soc Exp Biol Med. 1962;111(3):544-547. doi:10.3181/00379727-111-27849

23. Mert T, Yaman S. Pro-inflammatory or anti-inflammatory effects of pulsed magnetic field treatments in rats with experimental acute inflammation. Environ Sci Pollut Res Int. 2020;27(25):3154 3-31554. doi:10.1007/s11356-020-09401-z

24. Jain D, Mathur SR, Iyer VK. Cell blocks in cytopathology: a review of preparative methods, utility in diagnosis and role in ancillary studies. Cytopathology. 2014;25(6):356-371.

25. Szabo S, Trier JS, Brown A, Schnoor J, Homan HD, Bradford JC. A quantitative method for assessing the extent of experimental gastric erosions and ulcers. J Pharmacol Methods. 1985;13(1):59-66. doi:10.1016/0160-5402(85)90068-3
26. Necas J, Bartosikova L. Carrageenan: a review. Vet Med. 2013;58 (4):187-205. doi:10.17221/6758-VETMED

27. Fehrenbacher JC, Vasko MR, Duarte DB. Models of inflammation: Carrageenan- or complete Freund's Adjuvant (CFA)-induced edema and hypersensitivity in the rat. Curr Protoc Pharmacol. 2012; Chapter 5:Unit5.4.

28. Abu-Taweel GM, Mohsen GAM, Antonisamy P, et al. Spirulina consumption effectively reduces anti-inflammatory and pain related infectious diseases. J Infect Public Health. 2019;12(6):777-782. doi:10.1016/j.jiph.2019.04.014

29. Zhang H, Shang C, Tian Z, et al. Diallyl disulfide suppresses inflammatory and oxidative machineries following carrageenan injection-induced paw edema in mice. Mediators Inflamm. 2020;2020:8508906. doi:10.1155/2020/8508906

30. Otterness IG, Wiseman EH, Gans DJ. A comparison of the carrageenan edema test and ultraviolet light-induced erythema test as predictors of the clinical dose in rheumatoid arthritis. Agents Actions. 1979;9(2):177-183. doi:10.1007/BF02024731

31. Ben Khedir S, Mzid M, Bardaa S, Moalla D, Sahnoun Z, Rebai T. In vivo evaluation of the anti-inflammatory effect of Pistacia lentiscus fruit oil and its effects on oxidative stress. Evid Based Complement Alternat Med. 2016;2016:6108203. doi:10.1155/2016/6108203

32. Karim N, Khan I, Khan W, et al. Anti-nociceptive and anti-inflammatory activities of asparacosin a involve selective cyclooxygenase 2 and inflammatory cytokines inhibition: an in-vitro, in-vivo, and in-silico approach. Front Immunol. 2019;10:581. doi:10.3389/fimmu.2019.00581

33. Loram LC, Fuller A, Fick LG, Cartmell T, Poole S, Mitchell D. Cytokine profiles during carrageenan-induced inflammatory hyperalgesia in rat muscle and hind paw. J Pain. 2007;8(2):127-136. doi:10.1016/j.jpain.2006.06.010

34. Posadas I, Bucci M, Roviezzo F, et al. Carrageenan-induced mouse paw oedema is biphasic, age-weight dependent and displays differential nitric oxide cyclooxygenase-2 expression. $\mathrm{Br} J$ Pharmacol. 2004;142(2):331-338. doi:10.1038/sj.bjp.0705650

35. Vysakh A, Jayesh K, Helen LR, Jyothis M, Latha MS. Acute oral toxicity and anti-inflammatory evaluation of methanolic extract of Rotula aquatica roots in Wistar rats. J Ayurveda Integr Med. 2020;11 (1):45-52. doi:10.1016/j.jaim.2017.09.007

36. Nantel F, Denis D, Gordon R, et al. Distribution and regulation of cyclooxygenase-2 in carrageenan-induced inflammation. $\mathrm{Br}$ J Pharmacol. 1999;128(4):853-859. doi:10.1038/sj.bjp.0702866

37. Zhang J, Wang $\mathrm{H}$, Wang $\mathrm{T}$, et al. Anti-inflammatory activity of Yanshu spraying agent in animal models. Exp Ther Med. 2013;5 (1):73-76. doi:10.3892/etm.2012.761

38. Nakanishi M, Rosenberg DW. Multifaceted roles of PGE2 in inflammation and cancer. Semin Immunopathol. 2013;35(2):123-137. doi:10.1007/s00281-012-0342-8

39. Aoki T, Narumiya S. Prostaglandins and chronic inflammation. Trends Pharmacol Sci. 2012;33(6):304-311. doi:10.1016/j.tips.20 12.02 .004

40. Ozyazici T, Gurdal EE, Orak D, et al. Synthesis, anti-inflammatory activity, and molecular docking studies of some novel mannich bases of the 1,3,4-oxadiazole-2(3H)-thione scaffold. Arch Pharm. 2020;353 (7):e2000061. doi:10.1002/ardp.202000061

41. Li CL, Tan LH, Wang YF, et al. Comparison of anti-inflammatory effects of berberine, and its natural oxidative and reduced derivatives from Rhizoma coptidis in vitro and in vivo. Phytomedicine. 2019;52:272-283. doi:10.1016/j.phymed.2018.09.228

42. Cai C, Chen Y, Zhong S, et al. Anti-inflammatory activity of N-butanol extract from Ipomoea stolonifera in vivo and in vitro. PLoS One. 2014;9(4):e95931. doi:10.1371/journal.pone.0095931

43. Heeba GH, Mahmoud ME, El Hanafy AA. Anti-inflammatory potential of curcumin and quercetin in rats: role of oxidative stress, heme oxygenase-1 and TNF- $\alpha$. Toxicol Ind Health. 2014;30(6):551-560. doi:10.1177/0748233712462444 
44. Cidade AF, Vasconcelos PA, Silva DPB, et al. Design, synthesis and pharmacological evaluation of new anti-inflammatory compounds. Eur J Pharmacol. 2016;791:195-204. doi:10.1016/j.ejphar.2016. 08.033

45. Kumar KP, Nicholls AJ, Wong CHY. Partners in crime: neutrophils and monocytes/macrophages in inflammation and disease. Cell Tissue Res. 2018;371(3):551-565. doi:10.1007/s00441-017-2753-2

46. Othman A, Sekheri M, Filep JG. Roles of neutrophil granule proteins in orchestrating inflammation and immunity. FEBS J. 2021. doi:10.1111/febs. 15803

47. El Kebir D, József L, Pan W, et al. 15-epi-lipoxin A4 inhibits myeloperoxidase signaling and enhances resolution of acute lung injury. Am J Respir Crit Care Med. 2009;180(4):311-319. doi:10. 1164/rccm.200810-16010C

48. Bezerra Rodrigues Dantas L, Silva ALM, Da silva Júnior CP, et al. Nootkatone inhibits acute and chronic inflammatory responses in mice. Molecules. 2020;25(9):2181. doi:10.3390/molecules25092181

49. Sin YM, Pook SH, Tan TM, Pettersson A, Kara AU, The WF. Changes in glutathione and its associated enzymes during carrageenan-induced acute inflammation in mice. Comp Biochem Physiol. 1997;116(3):191-195.

50. Palaska E, Sahin G, Kelicen P, Durlu NT, Altinok G. Synthesis and anti-inflammatory activity of 1-acylthiosemicarbazides, 1,3,4-oxadiazoles, 1,3,4-thiadiazoles and 1,2,4-triazole-3-thiones. Farmaco. 2002;57(2):101-107. doi:10.1016/S0014-827X(01)01176-4

51. Begum MM, Islam A, Begum R, et al. Ethnopharmacological inspections of organic extract of Oroxylum indicum in rat models: a promising natural gift. Evid Based Complement Alternat Med. 2019;2019:1562038. doi:10.1155/2019/1562038

52. Naughton CA. Drug-induced nephrotoxicity. Am Fam Physician. 2008;78(6):743-750.
53. Sadek B, Hamruoni AM, Adem A. Anti-inflammatory agents of the carbamoylmethyl ester class: synthesis, characterization, and pharmacological evaluation. J Inflamm Res. 2013;6:35-43. doi:10.2147/JIR. S39743

54. Bjarnason I, Scarpignato C, Holmgren E, Olszewski M, Rainsford KD, Lanas A. Mechanisms of damage to the gastrointestinal tract from nonsteroidal anti-inflammatory drugs. Gastroenterology. 2018;154 (3):500-514. doi:10.1053/j.gastro.2017.10.049

55. Sriuttha P, Sirichanchuen B, Permsuwan U. Hepatotoxicity of nonsteroidal anti-inflammatory drugs: a systematic review of randomized controlled trials. Int J Hepatol. 2018;2018:5253623. doi:10.1155/ 2018/5253623

56. Saidu Y, Bilbis LS, Lawal M, Isezuo SA, Hassan SW, Abbas AY. Acute and sub-chronic toxicity studies of crude aqueous extract of Albizzia chevalieri Harms (Leguminosae). Asian J Biochem. 2007;2 (4):224-236. doi:10.3923/ajb.2007.224.236

57. Ozer J, Ratner M, Shaw M, Bailey W, Schomaker S. The current state of serum biomarkers of hepatotoxicity. Toxicology. 2008;245(3): 194-205. doi:10.1016/j.tox.2007.11.021

58. Junior SDA, Pereira PM, de Souza Tótoli V, et al. Incorporation of indomethacin into a mesoporous silica nanoparticle enhances the anti-inflammatory effect indomethacin into a mesoporous silica. Eur J Pharm Sci. 2021;157:105601. doi:10.1016/j.ejps.2020.105601

59. Deng X, Stachlewitz RF, Liguori MJ, et al. Modest inflammation enhances diclofenac hepatotoxicity in rats: role of neutrophils and bacterial translocation. J Pharmacol Exp Ther. 2006;319(3):11 91-1199. doi:10.1124/jpet.106.110247

60. Kim SY, Moon A. Drug-induced nephrotoxicity and its biomarkers. Biomol Ther. 2012;20(3):268-272. doi:10.4062/biomolther.2012. 20.3.268
Journal of Inflammation Research

\section{Publish your work in this journal}

The Journal of Inflammation Research is an international, peerreviewed open-access journal that welcomes laboratory and clinical findings on the molecular basis, cell biology and pharmacology of inflammation including original research, reviews, symposium reports, hypothesis formation and commentaries on: acute/chronic inflammation; mediators of inflammation; cellular processes; molecular

\section{Dovepress}

mechanisms; pharmacology and novel anti-inflammatory drugs; clinical conditions involving inflammation. The manuscript management system is completely online and includes a very quick and fair peerreview system. Visit http://www.dovepress.com/testimonials.php to read real quotes from published authors. 